Portland State University

PDXScholar

$4-1-1970$

\title{
Werner Bergengruens Erzählung Das Beichtsiegel als Seelendrama
}

Viola Maija Udris

Portland State University

Follow this and additional works at: https://pdxscholar.library.pdx.edu/open_access_etds Let us know how access to this document benefits you.

\section{Recommended Citation}

Udris, Viola Maija, "Werner Bergengruens Erzählung Das Beichtsiegel als Seelendrama" (1970).

Dissertations and Theses. Paper 941.

https://doi.org/10.15760/etd.941

This Thesis is brought to you for free and open access. It has been accepted for inclusion in Dissertations and Theses by an authorized administrator of PDXScholar. Please contact us if we can make this document more accessible: pdxscholar@pdx.edu. 
AN ABSTRACT OF THE THESIS OF Vlola Maija Udris for the Master of Arts in German, presented Apri1 15, 1970.

Title, Werner Bergengruen's Erzâhlung Das Belchts Legel als seelendrama.

APRROVED BY MEMBERS OF THE THESIS COMMITTEE:
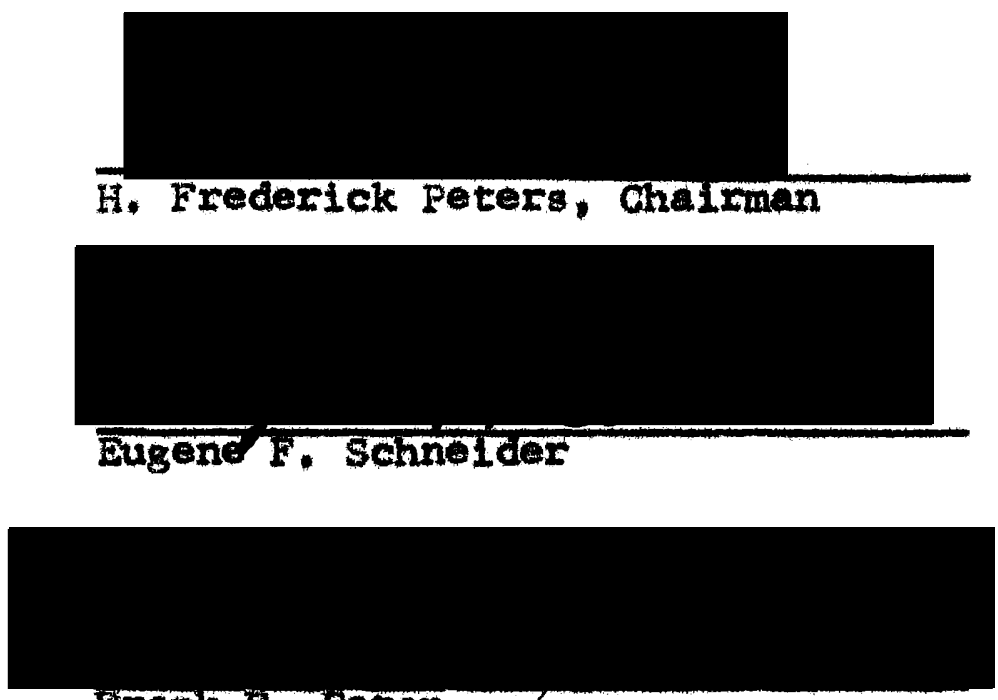

Frank waton

Werner Bergengruen has written Das Belehtslegel as a story, but I believe that exept for its narrative form, this story is a Seelendrame in the tradition of coethe's Tasso. Das Belchtsiegel answers the definition of a Seelendrana and fulfils its purpose.

In a seelendrana the action takes place within the soul of the hero. His soul is torn by an inner conflict. As it is Impossible to escape one's own soul, the conflict tears the hero apart. 
In the first part of my thesis I have made a comparison between Das Belchtsiegel and Tasso. This compariaon reveals that both characters, Goethe's Tasso and Bergengruen's Prlest Martin, suffer from conflicts of the soul, and these conflicts finaliy destroy each man in its inner-self.

In the second part of my thesis I have analyzed the reasoning and actions of Pxlest Martin. Through the confession of a atranger Martin finds out about an alleged murder plot against Princegs Ellsabeth, the daughter of Count von Thann-Ballenstein, whose confessor Martin is. The confession seals Martin's $11 \mathrm{ps}$ and forces him to live in constant fear. Martin tries in vain to protect Filsabeth from her alleged fate. The priest turns into a detective and Elisabeth's 11feguerd. In his soul there arises the conflict between his duty of confessional silence and his love for Ellsabeth. Finally Martin mist bow to God's w11 and admit that oach person must accept, bear and fult11 his own fate.

According to the dramste effect, I have divided Das Belchtsiegel Into five scenes, In which I have followed Martin's agony step by step. The secondary 11texature used In this part consists of thirteen sourees, which $I$ collected during my study year in Germany. 
WERNER BERGENGRUENS ERZÄHLUNG DAS BEICHTSIEGEL

ALS SEELENDRAMA

by

Viola Maija Udris

A THESIS

presented to the Department of Foreign Languages and the Graduate Council of Portland State University in partial fulfiliment of the requirements for the Degree of Master of Arts in German

April 1970 
TO THE OFFICE OF GRADUATE STUDIES,

The members of the Committe approve the thesis of Viola Maija Udris, presented April 15, 1970.
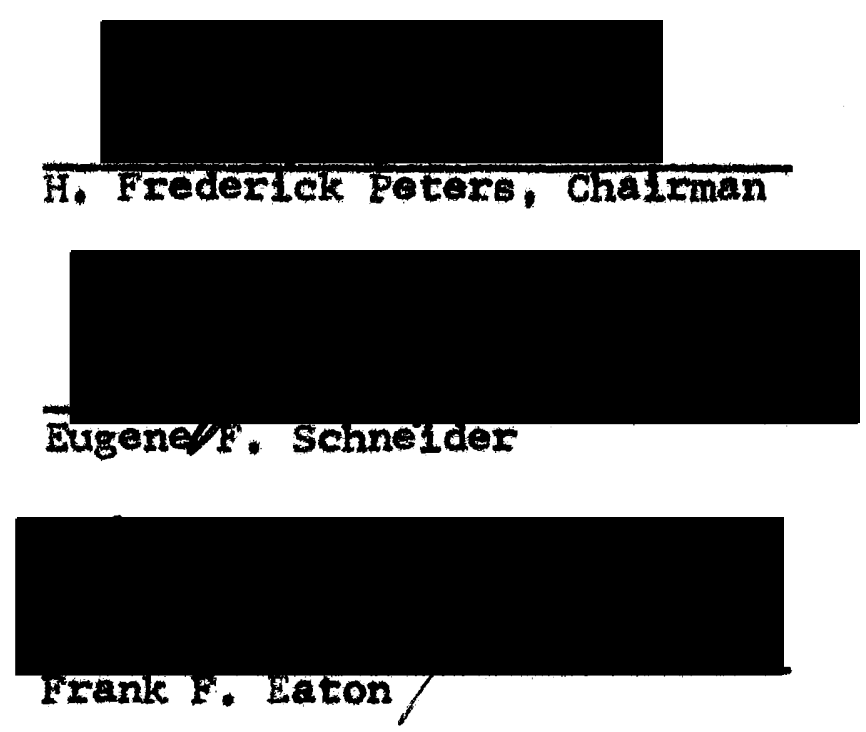

\section{APRROVED,}
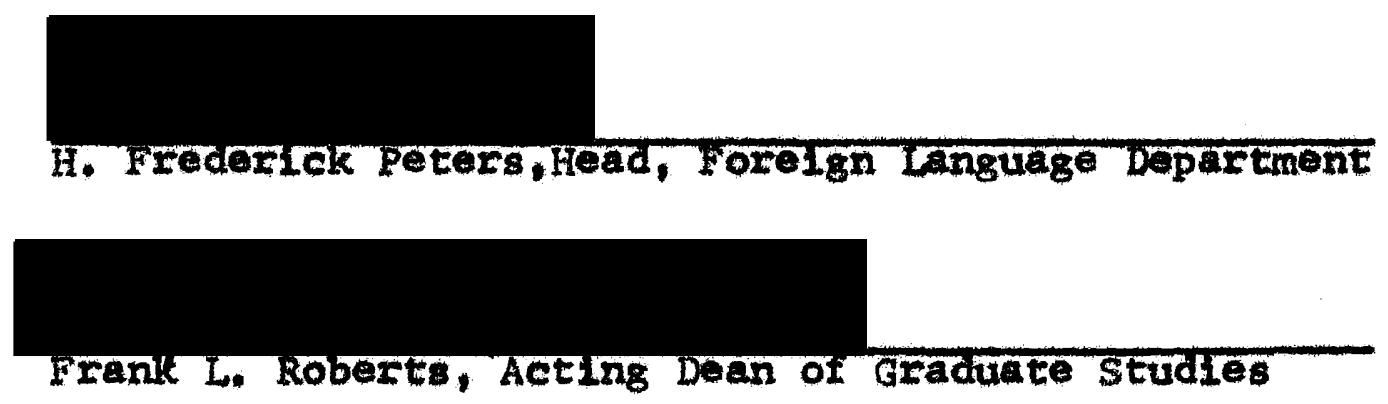

April 15, 1970 
WERNER BERGENGRUENS ERZÄHLUNG

DAS BEICHTSIEGEI ALS SEELENDRAMA 


\section{SEITE}

VORWORT, Die Aufgabe des Schriftstellers und

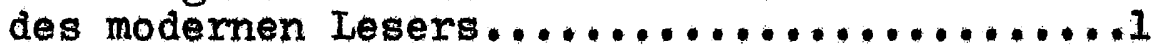

EINLEITUNG: Ein Vergleich zwischen den zwei Seelendramen, "Torquato Tasso" und "Das

Beichtsiegel".....................?

ERSTER TEIL, Die dre1 Hauptgestalten in Das Beichtsiegel

I Priester Martin Schbllhaas...........18

II Prinzessin Elisabeth von Thann-Ballenstein........................22

III Der Fremde am Beichtstuhl...........25

ZWEITER TEIL, Die Handlung in Das Beichtsiegel......28

I Die Schicksalsoffenbarung...........28

II Im Schatten des zweifels.............33

III Die goldenen Stunden der Freude.......43

IV In h8chster Verzweiflung............54

$\checkmark$ Der Besuch des fremden Gastes..........60

ABSCHLUSS: Die Seelenprobleme im Spiegel des

Schriftsteilers.....................64

FUSSNOTEN..............................68

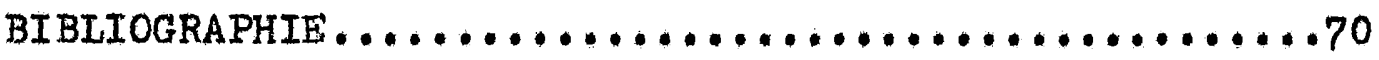


DIE AUFGABE DES SCHRIFTSTELIERS UND DES LESERS

Das Bleibende ins Bild zu stellen, das iat die Aufgabe des Dichters heute und morgen, wie sie es gestern und ehegestern gewesen ist.

Werner Bergengruen. Privilegien deg Diohterg

Jedes Buch ist ein magischer Spiegel, der die Seele des Dichters reflektiert und seine Gedanken, Winsohe und Hoffnungen enthillt. Der Dichter offenbart dem Leser seine Seele in bestimmten Bildern und Handlungen. Er schreibt, um zu leben, und er lebt, um uns seine Botschaft durch seine Schriften darzustellen. Ein Gedanke, den der Dichter nicht tbertragen kann, gibt inm keine Ruhe--gerade wie ine unerfullte Iiebe.

Manchmal hlingt die Handlung von einer bestimmten Ort $a b$ in anderes Mal sind zeit und ort nicht wichtig. Aber immer schrefbt der Dichter fur den aufmerksamen Leser und hofft, dass der Leser seine Botschaft verstehe. Denn der "magische spiegel" zeigt uns immer nur das, was wir darin sehen wollen. Fit den Leser ist es viel leichter, ein Buch schnell durchzublättern, und manchmal sieht er dann nur ein zerrbild--etwas, was der Schriftsteller inm nicht zeigen wollte.

Ein Buch ist das sch8pferische Geschenk des Schrift.stellers an den Leser, und es hat mehrere Aufgaben. Die Hauptaufgabe eines Buches ist, uns zu bilden und den Hori- 
zont unseres Denkens zu erweitem. Die zweite Aufgabe: ein Buch soll in geistvolles Unterhal tungsmittel sowie auch ein treuer und tröstender Freund sein. Sehr selten betrligt es den Leser...

Literatur soll dem Leser dienen. Aber ist es noch heute so? Die heutige Literatur ist oft nur eine Modesache. Der Leser sehnt sich nach etwas Sensationellem und or bekommt, was or winscht. Eine bessere Generation wilde aufwachsen, wenn an Stelle des Bosen das Gute in unserer heutigen Literatur mehr betont wirde. $z u$ viele Bllcher verherrlichen Iustmord, Habsucht, Nihilismus uns Sex. Deswegen sollte in unserer ohatischen zeit die Aufgabe des Buches sein, die Menschlichkeit in dem Menschen zu erwecken. Warum?

Der heutige Mensch ist meistens nur mit sich selbst beschaftigt. Fllr seine Mitmenschen hat or keine zeit und wenig Interesse. Was fthlt der Mensch unseres Jahrhunderts? Niemand will sich selbst in ein tiefes und echtes Mitgefthl verwickeln. Heute kann man ener Mitleid als Mitgefunl finden. Es ist viel leichter und schneller, elnfach zu sagen, "Es tut mir leid," als an dem Jeid selner Mitmenschen telizunehmen. Echte liebe ist selten, und das Wort "Treue" klingt irgendwie altmodisch und scheint nicht mehr in unsere zeit zu passen. Wer von einem anderen Treue begehrt, muss auch selbst Treue schenken. Aber der heutige Mensch hat nicht genug Mut dazu, einem anderen Menschen zu 
vertrauen. Um Verstllndnis fur seine Mitmenschen zu haben, muss man zuerst sein eigenes Herz 8 ffnen. Aber nu wenige Menschen haben diese Herzensbildung. Geduld nimmt zu viel zeit, und zeit ist fur uns sehr wertvoll. Die grosste Lebensschönheit findet sich gerade in den Beziehungen zwischen Menschen, aber auch die grössten Enttüuschungen und die tiefsten Schmerzen. Der Mensch sehnt sich nach dem anderen Menschen, denn eigentlich will keiner allein sein. Im Jenseits wird der Mensch von Gott erl8st, aber auf Erden kann ihn nur ein anderer Mensch befreien, der fur inn Verständnis hat.

Es ist eine grosse Strafe zu leben--vielleicht eine grbssere Strafe als zu sterben. Schon das neugeborene Kind muss sein Schlcksal tragen. Wenn der Mensch selbst physisch oder psychisoh nicht leiden muss, dann qualt inn die Untreue oder Ungeduld eines geliebten Freundes. Mehr oder weniger leidet jeder von uns unter metaphysischen Schmerzen ther das fast unertrligliche irdische Leben oder Uber das ungerechte Sch1cksal, Darum glaube ich, dass wir Bllcher lesen sollen, die das Leben des prometheischen Menschen be Jahen.

Solche prometheischen Geatalten finden wir in Werner Bergengruens Romanen und Novellen. Er beschreibt immer die Bezlehung zwischen Gott und dem Menschen.

Seine /Bergengruens/ Menschen stehen in der Entscheidung zwischen Gut und Bbse. Sie sind der 
Bedrohung aus dem Dunkel und ellen Angsten der Kultur ausgesetzt. Sie verstricken sich in sulnde und schuld und taumeln durch ein langes Leben der Gottesferne. 1

Warum wurde Werner Bergengruen Schriftsteller? In seinen eigenen Worten erkllirt er, dass seine Natur inm befehle zu schreiben:

\footnotetext{
Warum dichte ich?...Weil es ein offenbar elementares Bedurfinis meiner Natur ist, weil ich dem Triebe nachgeben will und muss, der mich von Prther Jugend an beherrscht hat, anders verm8chte loh nicht zu leben.2
}

Philosophen verschiedener zeitalter haben das irdische Leben verteidigt. Der Mensch muss auf der Erde leiden, damit er nach seinem Tode in ewiges Leben der Gnade leben kann. Doch ein starkes und braves Herz kann schon auf der Erde die Angst und die Schmerzen tberwinden und darf den Glauben nicht verlieren, auch wenn er in eine "Grenzsituation" hineingefthrt wird:

Den tiefsten Grund fur diese Reaktion der Menschen in der Grenzsituation sieht Bergengruen in der Furcht, im Schrecken vor dem Abgrund, der den Menschen bedroht. Dabei ist es zungehst einerlei, ob der Abgrund Tod, Schande, Folter, Geftangnis oder nur Verlust des Vermoggens bedeutet. 3

Der Nensch muss Schmerzen mit erhobenem Kopf tragen. Nur so unterscheldet er sich vom Tier. Das Schicksal wird inm schon in die wiege gelegt, und bis zum Grab muss or es tragen und ertragen. Das Thema in Bergengruens Werken ist "der Mensch vor Gottes Angeslcht"4. Der Schriftsteller 
analysiert die menschliche Seele und zeigt uns wie diese Seele auf verschiedene Lebenssituationen reagiert. Was braucht der Mensch, um sein Schicksal ertragen zu können? Er braucht Glauben, so dass or Uber die Leldenschaften triumphieren kann. Bergengruen bearbeitet germe religibse Probleme, denn

In der Katholischen Kirche sieht er die grosse Kultur---zugleich aber auch die besste Huterin der christliehen Botschaft in dieser Welt. 5

Weiterhin:

Er ist von der Botschaft der heiligen Schrift ergriffen worden--durch sie finden alle Dinge des Lebeng Ihren Sinn und damit inre rechte Stellung.

Bergengmen fuhrt seine Charaktere in einen Kreis hinein. Innerhalb dieses Kreises werden inre inneren Krätte erweckt. Die Menschen stehen vor der Erprobung inrer selbst. Sie enthüllen dem Leser inr Innerstes durch eine meist lebensbedrohende Situation. Der Schatten des Todes entblisst den Nenschen, und der Mensch ist allein mit selnem Schicksal. Gerade in dem Augenblick, wo er die Hilfe und Liebe seiner Mitmenschen am meisten braucht, ist er ganz allein und verlassen. Nur Gott, sein Schicksal und or sind da--das ewige Dreieck. Der Schriftsteller verurteilt seine Charaktere nicht. Er lässt den Leser selbst entscheiden, ob man ein bestimmtes Leben verurteilen kann. Aber he wir jemanden verurteilen, mulssen wir wissen, wieviel or in seinem Leben gelitten hat. 
Jeder von uns sollte Werner Bergengruens Erzathlung Das Beichtsiegel lesen. Dieses Buch zeigt uns, dass trotz beinahe unerträglicher Qual und Angst der Mensch--Priester Martin Sch81haas--sein Schicksal geduldig erträgt, gerade wie Prometheus. Kaplan Martin leidet jede Minute unter der seelischen Folter. Aber er gibt nicht auf. Und ein echtes und wertvolles Leben therzeugt uns mehr als eine Reihe von Predigtblichern. Man kann fragen, warum der Miensch so viel leiden muss. Hat Leid tberhaupt einen Sinn? In Privilegien des Dichters erkiärt uns Bergengruen,

dass es Dinge gibt, die um Ihrer selbst willen da sind, tm inrer selbst willen aufgenommen werden sollen, ausserhalb jedes menschlichen $\mathrm{Z}$ weckdenkens, es sei nun politischer, wirtschaftilcher oder moraIischer Natur in welchem sonst bis zur Unertriglichkeit alles Leben gefangen liegt.?

Das Beichtsiegel ist ein Trost für die mide Seele des heutigen Lesers. Was sehen wir, wenn wir in diesen "magischen Spiegel"hineinschauen? 


\section{EIN VERGLEICH ZWISCHEN ZWEI SEELENDRAMEN}

Jedes Zeitalter hat seine eigene lebensphilosophie entwickelt. Im zwanz1gsten Jahrhundert Uberwiegt der Nihi11smus. Im Schatten des immer drohenden Atomkrieges ist der Mensch glelchglitig geworden. Im Osten wird die Einzelpersớnlichkeit in den Massenmenschen verwandelt, im Westen dagegen verliert der Mensch sein Gesicht in Abstraktionen. Das Resultat ist der Chaosmensch unseres Jahrhunderts. Ober die Menschenseele spricht man heute selten, denn die Seele bedeutet etwas Schones und Edles, aber gerade heute wird das HEs liche und das Grausame verherr1icht.

Die Blutezelt der grossen Seelendramen, als Goethe Iphigenie (1787) und Torquato Tasso (1789) schrieb, ist Ilugst vorbei. Im Vorgleich zur vbervölkerung, Rassenfrage und Okologie scheint die menschllche seele ein unwichtiges und sogar 14stiges Problem zu sein. Was ist eine Seele? Im Worterbuch lesen wir, dass die seele der unsterbllche Te11 des Menschen--der Geist--ist. (The Grosset Webster Dietionary, Grosset \& Dunlap Publischers, New York, 1966 Edition). Der Mensch hat immer geglaubt, dass der Tod keine vollige Vernichtung sondern nur eine Umwandlung und ein Ubergang zu einem anderen Leben ist. Der K8rper zerfllit endlich in ein Nichts, aber die Seele bleibt unsterblich. 
Und diese Seele haben viele Dichter in Ihren Werken besungen.

Als ich Wermer Bergengruens Das Beichtsiegel gelesen hatte, musste ich an Goethes Torquato Tasso denken. Bergengruens Beichtsiegel, obwohl in der Form elner Erzăhlung geschrieben, ist in Wirklichkeit ein Seelendrama. In einem Seelendrama sind die Vorgänge subjektiv und innerlich, denn der Konflikt des Seelendramas findet in der Seele des Helden statt. Dieser innere Konflikt zerstört den Menschen und bringt inn langsam dem Untergang entgegen. Der Held kann seinem Selbst nicht entkommen.

Beide Hauptcharaktere, Goethes Tasso sowie Bergengruens Nartin Schollhaas, leiden unter unerträglichen Seelenkonflikten. Beide Werke entsprechen der obigen Definition eines Seelendramas und erfullen seine Aufgabe. Der Held wird nicht tusserlich sondern in seinem Inneren Wesen zerstört. Das Tragische ist nicht sein Tod, sondern sein Leben. Seine Seele entfremdet den Menschen sich selbst. Das Leben wird immer unertrkglicher, und die Seele wird immer ungeduldiger. Durch inre Konflikte treibt sie den Nenschen zur Verzweiflung, bis er sich sogar nach dem Tode sehnt. Der Tod scheint der einzige Ausweg zu sein, denn er befreit den Gequälten von seiner Pein und seine unruhige Seele von dem lastigen Korper fulr das ewige Leben. Aber in einem Seelendrama wird der Tod dem Helden oft versagt. Tasso findet den Ausweg im Wahnsinn, und Bergengruens Held, 
Martin, wird schwer verletzt. Der Schriftsteller sagt uns nicht, ob Martin den rettenden Tod findet.

Wenn wir Goethes und Bergengruens Werke vergleichen. finden wir viel Ahnliches. Goethe schrieb seinen Torguato Tasso in Weimar, als er im Bann von Frau von Stein stand. An inrer seite lernte er, dass "erlaubt ist, was aich ziemt" und nicht "was gefal1t". Im Tasso sehen wir die idealisierte Gestalt von Charlotte von Stein. Prinzessin Leonore ist Tassos Leben, und Frau von Stein war damals Goethes Ieben. Im Spiegel seiner Werke hat der Dichter Ihre Persbnlichkeit verewigt. "Ich habe gleich am Tasso schreibend Dich angebetet," schrieb er an Charlotte.

Goethe vollendete sein Drama 1789. Schon als JungIng kannte er die Werke des unglucklichen italienischen Dichters. Aber er musste selbst den zwiespalt zwischen der realen Welt und der idealen Welt der Dichtkunst erleben, ehe er Torquato Tasso (1544 - 95) kinstlerisch darstellen konnte. Dieser epische Dichter war elne seelenleidende Gestalt. An Tasso zeigt uns Goethe sioh selbst. Tasso (Goothe) ist ein ubersensibler Dichter, ein zweiter Werther, der am Hofe von WeImar (Ferrara) unglllcklich ist und Alfons dem $\mathrm{zwe}$ wen, dem Herzogen von Ferrara dienen muss. Tassos erster Konflikt ist zwischen Freiheit und Pflicht. "Der Mensch ist nicht geboren, frei zu sein". sagt Tasso. Herzog Alfons ist fur inn ein Herr, dem er als Dichter dient und Dank schuldet. Genau wie Tasso, ist 
auch der Priester Nartin Sch8linaas nicht frei. Als Priester muss er Gott dienen. Damit widmet er sein ganzes Leben seinen Mitmenschen.

Die Seit in Goether Werk ist genau angegeben. Im ersten Aufzug des Dramas uberreicht Tasso dem Herzog sein beendetes Gedicht Gerusalemme Liberata. Dies Gedicht wurde 1574 beendet. Obwohl die historische zeit das sechzehnte Jahrhundert ist, zeigt uns Goethe das Welmarer Hofleben des achzehnten und seine Freundschaft mit Frau von Stein. Auch Bergengruens Erzahlung spielt im achzehnten Jahrhundert. Der Schriftsteller erzthlt uns, dass Martin die Prinzessin Inrer Patronin, der heiligen Elisabeth, empfahl, die vor einem halben Jahrtausend lebte (Seite 36). Wir wissen, dass die Hellige Elisabeth von 1207 bis 1231 lebte. Die Novelle fägt kurz nach Ostern an und endet kurz nach Pfingsten. Sie dauert also ungefăhr sieben wochen.

Der Ort von Goethes Werk 1st der italienische (deutsche) Musenhof von Belriguardo (Weimar). Dort steht das ganze Leben und die Kultur unter dem zelchen der Asthetik. Kunstler geniessen da die höchste Verehrung. Das Schloss, grosszllgig gegen Mtinner des Geistes, wird von der Prinzessin so beschrieben. "...Hier wächst vor anderen Blumen die Myrte der Musen gern," Und Leonore Sanvitale stimmt zu. "...hier ward Petrarch bewirtet und gepflegt, und Arlost fand seine Muster hier. Italien nennt keinen gxossen Namen, den dieses Kaus nicht seinen Gast genannt". (Torquato Tasso, I. Aufzug, 1. Auftritt). Beide Prinzessinnen winden Kranze und 
bekränzen die Hermen Virgils und Arlosts. Am Hof von Belriguardo soll alles schön und edel sein, denn "ein edler Mensch zieht edle Menschen an und weiss sle festzuhalten". (I. Aufzug, 1. Auftritt)

Herzog Alfons der zweite ist ein Mazen der Kunst. Er unterstltzt Tasso, so dass dieser sein episches Gedicht Gerusalemme Liberata beenden kann. Der damalige Wettstreit zwischen den adligen Kunstmäzenen um die Künstler wird dargestellt, "Nur dass mir Scipio Gonzaga nicht, der kluge Medici lhn nicht entwendel" sagt Alfons Uber Tasso. (v. Aufzug, 1.Auftritt) Dle Kunstansichten des Herzogs werden so charakterisiert.

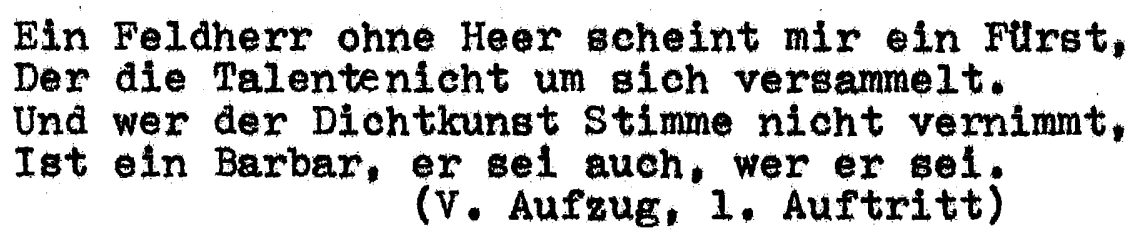

Der Ort im Beichtslegel dagegen ist unbestimmt. Wir wissen nur, dass die Handlung im Schloss Eremitage stattfindet. Wo befindet sich dieses Schloss? Nicht in Leningrad oder in Paris. In Russland regiert die russischorthodoxe Kirche, aber Martin ist ein katholischer Priester. Paris war im achzehnten Jahrhundert schon eine Hauptatadt, aber Martins Gemeinde befindet sich in einem städtchen mit einem "Fleischmarkt, Krautmarkt, Naschmarkt und Topfermarkt". Dazu gibt es noch eine Lateinschule bei Sankt Jakob und einen Kanal "dessen drel geschmungene Bricken mit weissen G8tterbildern geschmlickt waren," (Das Belcht- 
siege1, Seite 54). Das Leben am Hofe ist langwellig, da der Herzog von Thann-Balleinstein sich nur fllr die Jagd interessiert. Er ist "ein Feldherr ohne Heer."

Was fur ein Mensch ist Goethes Tasso? Er lst ein Dichter, dessen Leben nur einen einzigen Sinn hat:

Tasso:

Wenn ich nicht sinnen oder dichten soll.

So ist das Ieben mir kein Leben mehr...

(v. Aufzug, 2. Auftritt)

Er muss dichten, um zu leben, und leben, um zu dichten. "Jede Blume windet er zum Kranz," behauptet Leonore Sanvitale ther Tassos sch bferische Kunst. Lelder ist es schwer, einem leidenschaftichen, schöperischen Geist und einen bilrgerlichen Pflichtmenschen in einer Gestalt zu vereinigen:

Leonore:

...Sein /Tassos/ Auge wellt auf dieser Erde kaum, Sein Ohr vernimmt den Einklang der Natur;

Und sein Gefuni belëbt dä Unbelëbte.

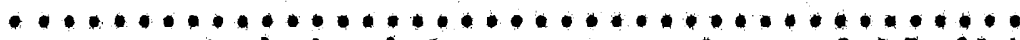

...er scheint sich uns zu nahn und bleibt uns ferm, (I. Aufzug, 1. Auftritt)

Tasso leidet an Reizbarkeit des Gefthls und einer Ubermalssigen Phantasie. Er gehort zu dieser Welt, doch das blirgerliche Leben bleibt inm frend. Tasso wird beim Hof verehrt und gellebt, aber zugleich ist or ein Einzelginger und ein "Milssiggelnger". Fur den praktischen Alltag hat er kein Interesse: 
Leonore:

... Immer fehlt es inm

An Geld, an Sorgsamkeit. Bald lässt er da

Ein Stuck, bald eines dort. Er kehret nie

Von einer Reise wieder, dass inm nicht

Ein Drittelteil seiner Sachen fehle. Bald

Bestienlt inn der Bediente...

(III. Aufzug, 4. Auftritt)

Ftir einen so vergesslichen Menschen sollte das sorgenfrei Leben in Ferrara ein Vergnilgen sein. Doch leidet Tasso sehr an Einsamkeit. Er ist menschenscheu und meidet die Gesellschaft. Tasso analysiert seine Mitmenschen nicht; entweder "fthlt" er einen Menschen oder nicht. Und Gefthle tåuschen oft. Tasso behauptet:

\section{Wer nicht die Welt in seinen Freunden sieht, Verdient nicht, dass die Welt von inm erfahre. ( I. Aufzug, 3. Auftritt)}

Doch kann er seine echten von den falschen Freunden nicht unterscheiden. Leonore Sanvitale liebt nlcht den Menschen Tasso, sondern den ruhmbekränzten Dichter. Duroh seine Werke hofft sie unsterblich zu werden. "Wie schön ist?s, in seinem schönen Geiste olch selber zu bespiegeln!" ruft sie aus... Wie ein Kind bietet Tasso seine Freundschaft dem klugen Diplomaten Antonito an and ist beleidigt, als Antonio seine Freundschaft ablehnt. "Der Ubereilte Knabe will des Mannes Vertrauen und Freundschaft mit Gewalt ertrotzen?" sagt Antonio spöttisch. (II. Aufzug. 3.Auftritt). Tasso wird misstrauisch und zuletzt muss er einsehen, dass nur Menschen, die dasselbe Schicksal tragen, Freunde werden 
können:

Die Menschen kennen sich einander nicht

Nur die Galeerensklaven kennen sich

Die eng an eine Bank geschmiedet keuohen. (v. Aufzug, 5.Auftritt)

Martin Schøllhaas findet langsam den Weg zur Liebe, aber Tasso verliebt sich in die Prinzessin auf den orsten Blick. Er gesteht ihr, dass er von dem "Gewimmel" dieses "drängenden Gefthls" ganz betalubt ist:

Welch ein Moment war dieser!

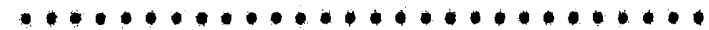
So war auch lch von aller Phantasie, Von Jeder Sucht, von jedem falschen Triebe Mit einem Blick in deinen Blick geheilt. (II. Aufzug, 1.Auftritt)

Als Tasso sein beeendetes Werk Alfons therreicht und damit den Herzog glicklich macht, sagt er zu lhm:

Euch zu gefallen war mein höchster Wunseh

Euch zu ergotzen war mein letzter zweck. (I. Aufzug, 3.Auftritt)

Aber als Alfons den Dichter später auf soin zimmer verbannt, fuhlt sich Tasso als ein Opfer, das unschuldig ist und doch bestraft wird--nicht nur bestraft, sondern auch betrogen.

Tasso:

Gehorchen ist mein Los, und nicht zu denken

Die Krone kleidet den Gefangenen nicht:

Ich nehme selbst von meinem Kopf die zierde. (II. Aufzug, 4.Auftritt)

Er nimmt den Lorbeerkranz ab, denn flir inn ist dieser Kranz 
kein Zeichen des Glltcks sondern des Leidens und der Beleidigung ,

In dem Beichtsiegel erfahrt Martin Schöllhaas von einem geplanten Mordanschlag auf Elisabeth, die Tochter des Futrstenpaares von Thann-Ballenstein. Martin, der Hofgeistliche, versucht dieses Verbrechen ohne Verletzung des Beichtgeheimnisges zu verhindern und die Prinzessin zu schltzen, was inm jedoch nicht gelingt. Nartin denkt, dass die Tochter des Markgrafen die bedrohte ist. Aber eigentlich ist Nartin selbst ein bedrohtes Wesen, nur weiss ex" es nicht. Er erlebt fast unertrïgliche Angst und am Ende weiss er, dass alle selne Bemthungen umsonst gewesen sind.

Tassos Seelenkonflikt ist"die Disproportion des Talents mit dem Leben," schrieb Goethe an Karoline Herder. Aus diesem Konflikt entwickelt sich eine Seelentragolie, die sich an dem Dichter vollzieht und inn am Ende vernichtet. Goethe zeigt uns Tassos zwiespalt der Seele an zwei Gestalten, dem leidenschaftilchen Dichter Tasso und dem realistischen Pflichtmenschen Antonio. Er zeigt uns auch, dass es unmoglich ist, den Phantasie - und Gefthlsmenschen Tasso mit dem literen erfahrenen Mann der Welt, Antonio, $\mathbf{z u}$ vereinigen. Antonio hat kein Verständnis fll Tassos jugendlichen tbermut und seine Trlume. Tasso dagegen funlt, dass Antonio ein kalter Diplomat und ein gefunlsloser Mensch 1st. Uber die zwei sagt Leonore Sanvitale:

Zwei Männer sind's, ich hab' es lang gefithlt, 
Die darum Feinde sind, weil die Natur

Nicht einen Mann aus innen beiden formte.

(3.Aufzug, 2.Auftritt)

Tasso funlt alles was inm fehlt, die Kraft zum praxtischen Leben, die Welterfahrung und die Urteilskraft. "...er /Antonio/ ist klug und leider bin ich's nicht," klagt er. Er kann die Gesetzlichkeit der Welt und sein kilnstlerisches Gefthlsleben nicht mit einander vereinen. Deswegen verschliesst sich Tasso vor der Gegellschaft und verliert sioh selbst. Als nach dem Streit mit Antonio Alfons dem Dichter-ohne böse Absicht---befiehlt, auf seinem zimmer zu bleiben, sieht Tasso sich vom Hofe verbannt und verstossen.

So hat man mich bekränzt, um mich geschmllckt Als Opfertier vor den Altar zu funren!

(v. Aufzug, 5. Auftritt)

Sein Missverstăndnis in der Liebe zur Prinzessin ist filr Tasso die letzte Hoffnung, sein Selbstgefuhl zu retten. Er sucht die Nathe Leonores auf, von der er Verstalndnis fur seinen menschlichen Wert erwartet. Die Prinzessin fulhlt fulr inn eine ehrenvolle Freundschaft, die an Liebe grenzt. "Ich muss inn ehren, darum liebt' ich inn," erklärt sie.(III, Aufzug, 2. Auftritt). Sie weiss, dass sie sich von Tasso entfernen muss, aber die Anzlehungskraft ist starker. Zwischen beiden steht die Gesellschaft mit inren Gesetzen. Aber Tasso kennt kein Mass der Vernunft, er ist ganz und gar Gefthlsmensch. Die Prinzessin ist sein 
Ideal, Er blickt zu inr in angatvoller Hoffnung empor, aber vor diesem Ideal kann or nicht bestehen und Leonores Liebe kann er nicht gewinnen.. Mit einem einzigen Wort, "Hinweg!" stösst sie Tasso von sich. Dieses Wort vernichtet Tassos Selbstgefthi und macht inn am Hofe unmög1ich. Durch diese hoffnungslose Liebe fur die Prinzessin wird Tasso zum Wahnsinn getrieben. Am Ende versucht Antonio das blosse Leben Tassos zu retten, denn sein höheres Wesen, seine Seele, hat der Dichter verloren. Martins Seelenkonflikt besteht zwischen seiner Pflicht--der absoluten Verschwiegenheit der Beichte--und seiner hoffnungsloser liebe für sein Beichtkind Elisabeth. Martins Seelendrama beschreibe ich in dem năchsten Kapitel. 
ERSTER TEI L

DIE DREI HAUPTGESTALTEN DER NOVELIE

Immer steht der Mensch in der Mitte.

Werner Bergengruen

Schreibtischerinnerungen (Seite 126) 


\section{DER PRIESTER MARTIN SCHOLIHAAS}

Wenn ein Mann zum Priester geweint wird, dann widmet er sein ganzes Leben Gott und seinen Mitmenscher. Seln personliches Leben muss er fur sein kirchliches Amt aufgeben. Er wird ein Medium, durch das die Gemeinde das Wort Gottes und die Sakramente erhalt. Nach der Beichte gibt der Priester dem Beichtenden die Absolution als Bestatigung der Gnade. Die Lippen des Priesters sind durch das Beichtsiegel verschlossen, und or darf es nie verletzen.

Pater Schollhaas, der Beichtvater der markgraflichen Familie von Thann-Ballenstein, muss wegen eines Erbstreites verreisen. Sein Neffe Martin Schblihaas wird gein Stellvertreter. Martin ist noch ein sehr junger Niann, aber or hat schon selne eigene Gemeinde an der Kirche von HeiligLeichnam. Von seiner Familie wissen wir nichts. Er hat nur seinen Ohelm, der inm eine gute Ausbildung geben liess, Martin ist ein ausgezelchneter Redner. Seine stimme ist "lebhaft und vieler Wandlungen făhig". Es ist unmbglich, inr "die Aufmerksamkeit zu versagen". Im Gespräch redet or freimitig und ohne oberhebung. Aber wenn or als Priester spricht oder eine Vorlesung hält, dann gluhen seine worte wie Kohlen. Aus innen strömt eine Glut und eine heimliche Leldenschaft, die seine zunbrer und auch inn selbst fortreissen.

Da seine Redeweise und Benehmen dem Narkgrafen gefallen, bekommt Martin die stelle des personlichen Beicht- 
vaters der markgräflichen Familie und des Schlossgeistlichen. Seine Hauptaufgaben: er soll jeden Morgen die Messe in der Sphlosskapelle lesen und an Sonntag predigen, falls der Markgraf es wilnscht. Martin will es mit den Obliegenheiten seines Amtes genau nehmen.

Wir sehen Martin durch die Augen der Prinzessin Elisabeth als "einen Priester, wie von den Farben der Legende gemalt". Er 1st sch on und schlank mit einem kthngeschnittenen Gesicht. Er ist weder schwerfullig noch ungeschliffen. Im Gegenteil, er ist feurig und leidenschaftlich. Er trägt seine Soutane nicht wie einen Schlafrock, sonderm wie eine Toga. Elisabeth sieht in Martin einen Griechen oder Römer des Altertums und zugleich einen jugendlichen Heiligen. Martin selber denkt, dass seine Jugend schon längst vorbei ist... Beim Ballspiel erklät er Elisabeth "er habe als junger Manncauch den Federball geschlagen", Mit diegem Ausspruch gewährt uns Martin Einblick in seine Seele: die Last seines Amtes, die väterliche Verantwortung für seine Mitmenschen haben inn vor sich selbst gealtert, obgleich die, die um ihn sind, in ihm einen jungen Mann sehen. Martin igt bei den Menschen beliebt, dennoch ist ex einsam. In der Novelle hat er keinen Freund, dem er sein Herz ausschutten kann. Er kann nur mit seinem Ohelm oder dem Bischof sprechen, aber beide sind abwesend.

Jedem Menschen ist sein eigenes, unvertauschbares Schicksal zugedacht, und hinter diesem steht nicht 
Willkür oder Bosheit, sonderm es stemnt aus derselben Wurzel wie er selbst, kann inm also nicht feindlich sein.Es entspricht der Natur, den Wesensgesetzen eines jeden Menschen und hat diese zur Erftilung zu fuhren.8

Jeder einzelne Mensch ist wichtiger als die ganze Menschheit. Er hat eine bestimnte Lebensaufgabe, die er erfulien muss. Diese Lebensaufgabe nennen wir das Schicksal, doch wir wissen nicht, was fur ein Schicksal uns zubertimmt ist. Der unwichtigste Mensch ist wichtiger als die schönste Idee, denn es gibt keine Idee ohne elnen Menschen. Der Mensch denkt, aber Gott schafft. Martin denkt, dass er der Beichtvater in Schloss wird, aber eigentlich wird er der Wachter Elisabeths. Martin will seine Mitmenschen trösten, aber nach der Belehte des Fremden misstraut er jedem fremden Menschen, den er in der Năhe Elisabeths sieht. Er soll die Schonhelt des Schopfers loben, aber sein Schicksal befiehlt inm, diese Schbnheit uberhaupt nicht zu bemerken. Anstatt Glauben findet Martin in seinem Herzen nur Verzweiflung, und ewige Angst fur sein Beichtkind Elisabeth, deren Leben bedroht ist, vernichtet seine schönsten Gedanken und Hoffnungen.

Durch die Beichte eines fremden Mannes wird der Priester in die Hölle der Verzweiflung gestürzt. Whathrend einer späteren Beichte desselben Mannes wird Nartin schwer verletzt, denn "...erst durch das Opfer gelangt der Mensch zu seiner eigentlichen Bestimmung". 9 Martin geht einen Opfergang, denn ein Geistlicher soll nach dem Gebot der 
Kirche seine Pflicht gegeniber anderen Menschen erfulien. Bergengruen zeigt uns, wieviel ein Priester ertragen kann und warum er sich seinem Schicksal beugen muss. Martin morchte geme seinem Sohicksal ausweichen und sogar seine Steliung verlassen, aber das kann er nicht. Fur inn gibt es keinen Ausweg aus dieser "Grenzsituation" zwischen Glauben und Angst. Er muss die inm auferlegte Zerreissprobe bestehen. Nur dann wird er erlost. 


\section{PRINZESSIN ELISABETH VON THANN-BALLENSTEIN}

Neben den harten und schweren gibt es auch lelchte und glulckliche Alltagsschicksale, die ohne grosse Erschultterungen dahingleiten. 10

Prinzessin Elisabeth ist das einzige Kind des Markgrafenpaares von Thann-Ballenstein. Sie ist mit dem Prinzen Georg-Phillip, dem Sohn eines benachbarten Furstenhauses, verlobt. Die Hochzeit soll in einigen Monaten stattfinden.

Elisabeth verbrachte eine behlltete Kindheit und Jugend. Inre Ausbildung unter inrem Lehrer, Martin Scholihaas's Oheim, war ungeordnet. "Vieles ist mit mir angefangen, aber wenig zu Ende gefuhrt," sagt die Prinzessin ther inre Ausbildung. Elisabeths Gesicht ist schon und zart, und sie hat Augenbrauen von ebenmassiger W8lbung. Das Kinn und die kreftig gebildete Nase erinnern an inren Vater. Elisabeth hat eine weisse Katze und einen Kanarienvogel. Hunde mag sie nicht. Sie spielt gern Federball mit inren beiden Ehrendamen. Fräulein von Beckum, "ein rotbăckiges, lachlustiges Geschöpf" begleitet die Prinzessin tberall.

Elisabeths Verlobter, Prinz Georg Phillip, ist ein Leidenschaftlicher Liebhaber der Jagd, der Pferde-und Hundezucht. Besonders liebt er die Parforcejagd. Er hat seine zukünftigen Schwiegereltern gebeten, dafur zu sorgen, dass Elisabeth sich Jagderfahrung aneigne, die sie als seine Frau werde betatigen milssen. Er winscht, dass seine 
Braut sich in Musik, im Kartenspiel und im Italienischen vervolikomme.

Als Nartin der Beichtvater der markgräflichen Familie wird, wilnscht Elisabeth, sich einigermassen auszubllden. Am liebsten würde sie Lateín lemen, so dass sie bestimmte Werke theologischen Inhaltes lesen könnte. Aber die zeit dafur ist zu kurz, denn die Hochzeit steht vor der Tir. Deshalb winscht sie regelmässige Lesungen $z u$ bestimmten Stunden. Nartin Schollhaas soll der Vorleser und Ausleger sein. Die Prinzessin stellt auch die erste Frage an Martin. Sie ist schulchtern von Natur aus, aber diese Scheu uberwindet sie langsam. Trotz inrer ungeordneten Ausbildung bezeigt sie eine überraschende geistige Schärfe und Klarheit.

Elisabeths Vater, der Markgraf, ist ein "kurzatmiger" Niann mit "heckenartigen" Augenbrauen. Er liebt die Schnepfenjagd. Die Mutter der Prinzessin ist eine früzeitig ermüdete und "in täglichen Gewohnheiten verkühlte" Frau. Sle hat weisse kurze Hände mit vielen Ringen, die sie mehrmals des Tages zu wechseln pflegt.

Elisabeth ist das unwissende Opfer der Erzählung. Sie hat keine Ahnung davon, dass inrem Leben Gefahr droht. Sie weiss nichts von dem grausamen Mordplan gegen sie. Sie lebt und lacht. In seinen Gedanken nennt Martin sie "die Braut des Todes", doch,

Der Mensch weiss nie, was er vor sich hat, er kennt 
das Ziel des Weges nicht, auf den er gestellt ist, vermag die Krafte und Mlachte, die inn und die Welt regieren, nicht zu durchschauen. II

Elisabeths Schicksal fuhrt sie nicht in den Tod,denn sie wird nicht ermordet...

Wenn Martin die Prinzessin ansieht, funlt or den schleichenden Tod an Elisabeths Seite stehen. Er weiss, dass der Tod immer dabei ist, aber er annt es nicht, dass anstatt der Prinzessin. Martin selbst von inm betrachtet wird. Er sieht Elisabeths Gesicht verzerrt von den Qualen des Todeskampfes, aber er sptrt es nicht, dass sein eigenes Leben in Gefahr ist. Die ewige Frage: "Was fü ein Tod ist inr bestimmt?" plagt Martin Tag und Nacht. Elisabeth merkt es nicht, dass sie von Martin bewacht wird. Martin gefallt inr. Er gefdllt ihr mehr, als in Priester sollte, und deswegen bittet sie inre Eltern, die Lesestunden zu unterbrechen. Die Prinzessin ahnt, dass inrem jungen Herzen eine neue Gefahr droht, und dieses Gefuhl erweckt die Angst in inr, die von Anbeginn in jedem Menschen schlummert. 
Der fremde Beichtende ist "der Urheber aller Muhsale und Irrnisse" in der Erzthlung. Mit seiner Belchte fuhrt er den Priester Martin Scholihaas in die tiefsto Verzweiflung und entfremdet Martin soger sich selbst und seiner priesterlichen Aufgabe. Der Fremde 8 ffnet Martin die Tur zur Grenzsituation, und der Priester muss von nun an zwischen Glauben und Angst leben, bis die Erzâhlung inren Zweck erfullt hat. Nur dann befreit das Schicksal Martin von dem fremden Beichtenden.

In der Novelle treffen wie diesen fremden Mann nur zweimal das erste Mal im Beichtstuhl in der Heilig-Leichnam Kirche und das zweite Mal im Gasthaus "Roter Ochs". Er ist ein relsender Handelsmann "aus UIm oder Esslingen". Er hat schwer gestindigt und will seine Seele bei einem Priester entlasten, um durch seine Beichte eine Lossprechung zu erreichen.

Er /der Mensoh/ ist in Glied der gefallenen und selbst dümonisch besessenen Natur, aber zugleich, sofern er Christ ist, Gesegneter der sakramentalen Welt..."12

Dieser "dămonisch besessene" Mann hat an einem Unternehmen teil, dessen ziel die Beseltigung der Prinzessin Elisabeth ist. Er ist durch einen Schweigeeid gebunden, aber er will durch die Beichte sein Herz erleichtern und sich nach der Lossprechung aus der Verschwörung zurlickziehen. Er darf tber den Plan des Mordversuches nicht 
sprechen, denn er furchtet die Rache seiner Mitverschworenen und kann auch keinen Verrat Uben. Deshalb will der Beichtende keine weiteren Auskinfte geben, damit die Untat verhutet werde, nicht einmal in einem versiegelten Brief. Er will auch keine Belohnung vom Narkgrafen fur die Auskunft lber seine Mitverschworenen empfangen. Martin muss darum dem "schweigenden" Mann die Lossprechung verweigern, da der Vann an den Sunden anderer teilgenommen hat. Er will "ein Bbøes tun und ein Gutes unterlassen" und dazu schweigt or noch und will die Untat garnicht verhindern. Der Fremde verlässt den Beichtstuhl mit der Hoffnung, dass ein anderer Priester inn absolvieren werde. Martings Gedanken kehren immer wieder zu dem Beichtenden zurilck. Der Priester hat das Gesicht des Fremden durch das Gitter des Beichtstuhles gesehen, aber er weiss nicht, wie alt der Beichtende ungefăhr ist. Aber seine Stimme und seine Mundart wirde er bestimmt wiedererkennen. Das zweite Mal treffen wir den Beichtenden im Gasthaus zum "Foten Ochsen". Wieder versucht er, bei Martin Sch8IIhaas seine Seele zu entlasten. Diesmal will ereuber die Untat beichten, aber es ist zu spät. Es fallt ein Schuss, die Fensteracheibe wird zersplittert, und der Mann stirbt, ehe er eine Gelegenheit hat, seine Beichte zu beginnen. Als Martin sich ther den Sterbenden beugt, wird auch or von einer Kugel verletzt.

Der fremde Beichtende fthrt Nartin in dio Holle auf 
Erden und dann wieder heraus. Seine Seele ist geduldig, aber nicht mutig. In seinem Herzen

... wird der Kampf zwischen Gut und Böse bis zum Ende der Zeiten weitergeklmpft....denn Sundenfall und Erlosung sind fur den ehristlichen Dichter die Angelspunkte der menschlichen Existenz. 13 
Z W E T ER TE I L

DIE HANDLUNG IN DER NOVELIE 
EIN SPANNENDES DRAMA IN FUNF SZENEN 


\section{DIE SCHTCHSALSOEFENBARUNG}

Das lat Cotter Gewohnhelt, or funrt in dio Ho110 und Leder Hexaus. Heznex Bargentruen. Pelugexa

Dor Menseh kan gein Jeben nur deahalb ertragen. we11 ex niont weles, was das Sohleksal inm botimmt hat. Wenn or mit su grovar Hofmung selnem Schlohat entgogentxitt. wind en entthuscht. Wenn or versuent, dem Sehloker au dem Wege zu gehen, wird or In die Tlefe gerisen. Was blelbt den tensohen also Abrig? Er muse vein Schloksal anmehmen und vexeuchen, alch daxuber a exheben. BergenGruen behendelt seine charaktere wi Schaohfiguien in elnem Sehlekeresplol,

Bergengruen beglnnt die Handiung in geInen Verken danit, dase or don Menschen aus dem Alltag und Ruhepunkt in Borthrung mit dem Sohlokeal bringt, Man Jamn diese Exofmung der Handiuns mit der Eroftnung beim sohecheplel verglelohon, ale of boetlinmend fir die weltere Entwieklung des spieles wird.14

Ala Pator Schol.1haus, der Belohtvater der markgrif-

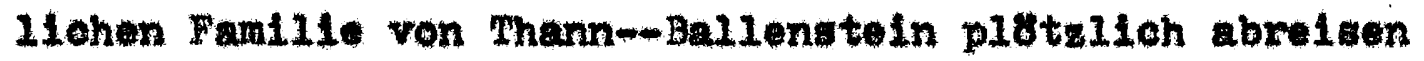
muss und seinen Jungen Neffen Kartin ale seinen molichen stellvertweter dem wargrafon vorste11t, wi11 or Martin nux helfon, elne influserelohe nebonberufliche stellung su beklelden. Pater Seholihaas hat kelne Ahnung davon, dase or beInen Nefien Ins Unglitek tosst. Das Sehleksal hat 
andere P1äne fitr Martin:

Es kommt also zu einem Zusammenstoss zwischen dem Menschen und dem inm angetragenen Schicksal,
einem Zusammenstoss, dem man nicht entgehen kann. 15

Martin Sch81lhaas hat seine eigene Gemeinde. Er ist Kaplan an der Kirche von Heilig-Ieichnam. Trotz seiner Jugend erhalt er die Stellung im Schloss und wird Belchtvater der markgriflichen Familie. Die Geschichte Tassos beginnt mit einem Lichelni die Geschichte Nartins mit Hoffnung auf Erfolg.Doch am Tage vor dem Antritt seines neuen Amtes geschleht der "Zusammenstoss mit dem inm angetragenen Schicksal", als er die Beichte in Heilig-Leichnam hören muss, steht am Beichtstuhl ein fremder Mann, der veine Seele erleichtern will. Aber gerade die Beichte des Fremden fihrt Martin in ewige Angst und seelische Qual. Sie versetzt inn in Schrecken, Sorgen und Misstrauen, die er nicht tberwinden kann. Denn wenn ein Mensch von einer schrecklichen Angst befallen und spatter uberwlitigt wird, dann wird das Ieben fur inn eine Holle auf Erden.

Als der Beichtende mitteilt, dass or mit anderen Mitwissenden einen Mordanschlag auf Elisabeth, die Tochter des Markgrafen, plant, erschrickt Martin sehr. In seinen Schreibtischerinnexungen erklärt Bergengruen, dass "die Angst ein menschlicher Urzustand, eine menschliche Urstinde und in menschliches Urbedurfnis sel" (Seite 130). Seiner Meinung nach ist die Angst eine menschliche Krankheit, und 
der Mensch soll dieser Krankheit widerstreben. Diese Krankheit wird Martin nie verlassen. In diesem Moment wird der Priester von Bergengruen in "eine Lage versetzt... die inm nichts erspart". 16

Wie reagiert Martin auf diese spannungsvolle Situation als Belchtvater? Bergengruen zeigt uns, dass auch in Geistlicher ein Mensch mit allen menschlichen Schwächen ist. Vielleicht ist die grosse Angst daran schuld, dass Martin ein ungeduldiger Beichtvater wird und sogar im Beichtstuhl sundigt. Wahrend der Belchte soll er sich einzig auf die seele des fremden Nannes konzentrieren. Er sol1 dem Mann genug zeit geben, seine Sinde zu bereuen und Inn von der Todesangst befreien. Nur Angst hat diesen Mann zum Beichtstuhl getrieben--da sieht er seine Rettung. Er will sein Gewissen entlasten, aber or hat Angst vor der Rache der anderen Mitwisser des Mordplanes. Er will kein Verräter sein, denn dann wird er selbst umgebracht. Darum schweigt er.

Martin sindigt, da er in diesem Augenblick mehr an die Sicherheit Elisabeths als an die Rettung einer sundigen Seele denkt. Natürlich will Martin mehr tber den Mordplan wissen. Er muss schnell einen Weg finden, womit er Elisabeth retten kann. Der Beichtende kommt erst an zweiter Stelle. Er sagt nicht, wann der Mord ausgefunrt werden s011. Doch Martin ist sicher, dass der Mord kurz vor Elisabeths Hochzeit erfullt wird und nur von der Seite 
des Brăutigams der Prinzessin ausgehen könnte. Nartin sulndigt wieder. In seinem Gewissen hat or Elisabeth schon zum Tode verurte1lt, die zeit inres Todes bestimmt und gegen die Familie des Brăutigams Verdacht gehegt. Im Beichtstuhl vergisst er, dass nur Gott weiss, wann die Stunde jedes Menschen geschlagen hat. Aber "auf Gottes Kosten darf kein Pakt mit den Wächten der Welt geschlossen werden."17 Die Frage ist, wer von den Beiden ist der grössere Sunder, der Fremde oder der Beichtvater?

Der Fremde will sich "mit unbeschädigter Seele aus der Verschworrung zurtickziehen". Aber kann ein Mensch tberhapt eine unbeschädigte Seele haben, wenn er elnem anderen Menschen das Leben nehmen will? Wenn er am Beichtstuhl schweigt, hat er seine Seele schon dem Teufel angeboten. Martin versucht vergebens, seine Strategie weiterzufthren. Er will wenigstens versuchen, die geplante Untat zu verhindern. Der Fremde könnte seine Aussagen anonym in einem Brief Nartin ubergeben. Martin weiss, dass Geld ein mächtiges Mittel der Uberzeugung ist. Er spricht weiter von elner Belohnung, die der Markgraf dem Lebensretter seiner Tochter bestimmt tberreichen wilde. Doch die rodesangst ist mächtiger als Geld.

Zuletzt versucht Martin "den Nachdruck auf das Geistliche zu legen". Wenn ein Beichtender solch eine Untat verschweigt, dann ist die Beichte "unvollständig" und darum "ein Gottesraub". Solch ein Mensch wird von Gott ver- 
lassen, da er das Haus Gottes missbraucht. Martin sagt, es wäre die Pflicht des Nannes zu reden. Gerade das Reden wilde die Strafe sein. Wenn der Fremde den sulndhaften Schwur nicht bricht, kann er nicht absolviert werden. Martin verliert die letzte Hoffnung, als der Mann den Beichtstuhl verläast, um eine lossprechung bei einem anderen Priester zu suchen.

Diese kurze Szene zeigt uns, dass ein Priester auch nur ein Mensch ist und sich irren kann. $\mathrm{zu}$ dem Beichtenden spricht er von Pflicht, Sünde, Geld und Strafe. Aber er spricht nicht von Mienschenliebe, Hoffnung und Hilfe. Er sollte dem Sunder Zeit geben, seine Entscheidung nochmals zu therlegen. Er sollte inn nicht einfach weggehen lassen, sondern inn einladen zurlickzukommen. Der Fremde weiss selbst, dass er eine Todsunde auf seinen Schultern trägt. Er braucht Verstindnis und einen Menschen, der ihn trösten kann. Der Beichtende welss auch, dass kein anderer Priester inn unter diesen Umständen absolvieren wird. Er läuft ohne Hoffnung, von Angst getrieben, fort. Diese unvollendete Beichte verwirrt Martin. Er macht keinen Versuch, dem Fremden zu folgen oder inm nachzuforschen. 


\section{S Z E N E I I}

\section{IN SCHATTEN DES ZWEIFELS}

Der Alltag des Menschen ist weitgehend bestimmt von der Spannung zwischen $\mathrm{zweifel}$ und Glauben, zwischen Unruhe und Gewissheit. Denn aller Glaube ist in Wagnis. 18

In dieser Szene zeigt uns Bergengruen in einer chronologischen Reihenfolge wie Martin auf seinen Schicksalsschlag reagiert, was er denkt und wie "diese dunkel wirkenden Krofte des Schicksals Ihn Ubersteigen".19

Schon bei Tisch wăhrend der ersten Mahlzeit im Schloss wird er von schrecklicher Angst gepackt! in jeder Speise auf dem Tisch kbnnte Gift sein. Aber der M8rder wille doch nicht die ganze Hofgesellschaft gefürden. Die Mahlzeiten werden fur Martin eine unendliche Qualerei, und die Năchte verbringt or in Unruhe. Woran denkt er in diesen langen Nächten?

Erstens: er darf das Beichtsiegel nicht brechen. Zweitens, sein Beichtkind Elisabeth muss geschlltt werden. Drittens, or allein muss der Wissende bleiben, und viertens, er muss geheim handeln. Schliesslich muss er eine Kriegsstrategie entwickeln, um trotz des Beichtgeheimnisses die Prinzessin beschlltzen zu können. Martin muss den goldenen Mittelweg finden. Wüde er dem Markgrafen erzălen, er wisse durch eine Beichte, dass Elisabeths Leben Gefahr drohe, dann verletzte or doch das Beichtsiegel. Falls er nichts unternehme und die Prinzessin doch getotet wilrde, 
dann whre er an inrem Tod schuldig. Welche Lbsung bleibt inm also Ubrig? Seine Rolle als Beichtvater ist eigentlich fur inn nur ein Scheinamt. Seine allererste Pflicht ist es, Elisabeths whyter zu sein. Aber wie kann man sie am besten und möglicherweise immer unter Aufsicht haben?

Martins erster Gedanke ist es, sich Einfluss auf die alte Markgrafin zu erwerben. Also: durch die Mutter zur Tochter. Er muss von Elisabeths Nutter die Tageseinteilung und die Lebensgewohnheiten der Prinzessin zu erfahren versuchen. Dann muss auf irgendeine Weise diese Tageseinte1lung andern, um so den Mordplan zu verhindern. Nur dusch die Nutter hofft er, einige Anderungen in Ellsabeths Leben zu bewirken.

Martin wird langsam von der Angst ubermannt. Und Angst hat grosse Augen, in Mensch in Angst sieht Gefahren, die in Wirklichkeit gar nicht exisitieren. Wenn Martin durch den Laubengang zum Ballplatz geht, eilt er. Keine Minute darf er verstumen. Er muss in Elisabeths Nathe sein, denn die Laube könnte einen Mörder verbergen. Jemand konnte die Prinzessin jeden Moment töten, wenn er sie nicht beschlltzt... Nan sagt, dass ein Mensch liebt, wenn er fur seinen Mitmenschen zu sterben bereit ist. Ohne zogern ist Martin bereit, sein Leben fur Elisabeth zu opfern. Nur fur inn ist es kelne Liebe, sondern eine menschliche Pflicht. Wie reagiert Elisabeth auf sein Pflichtgefthl?

Als Martin atemlos den Ballplatz erreicht, fragt inn 
Elisabeth 1ächelnd, ob das Ballspiel inm gefalle. Sie bemerkt gar nicht die Panik in Martins Seele. Unwissenheit weiss nichts von Angst. Elisabeth ist jung und geniesst das Leben. Mit ernstem Gesicht antwortet Martin, dass er als junger Mann auch Federball gespielt habe. Er ist jung, aber wenn ein Mensch unter dauernder Angst lebt, scheint er sich selbst alt.

Seln zweiter Plan ist, Elisabeth zu besuchen. Er muss sein Beichtkind besser kennenlemen. Es obliegt inm als Beichtvater, sich nach inrer letzten Beichte, Kommunion und Ihren Andachtsubungen zu erkundigen. Aber ist es auch seine Pflicht, inr Gesicht jede Sekunde zu beobachten und, statt Ellsabeths seelischen Zustandes, "die krlftig gebildete Nase und die schonen Augenbrauen" zu studieren?

Er /der Mensch/ wird gezwungen, auf die inm bekannten Sicherungen zu verzichten und sich der im Dunkel auf inn wartenden Gefahr statzenlos und schutzlos entgegenzustellen und ihr aus der eigenen Kraft Widerstand zu leisten. 20

Jede Antwort Elisabeths und jeder Gesichtsausdruck von inr konnten Ihm helfen, den Mordplan zu verhindern. Jede Einzelheit in Elisabeths Leben lst wichtig...

Gerade whthrend des Gesprächs mit der Prinzessin splirt Martin "den dunklen, schleichenden und geheimnisvollen Tod" so nah wie noch nie zuvor. Die Ironie ist hier, dass or den Tod nur hinter Elisabeths Rücken sleht, aber keine Ahnung davon hat, dass der Tod inn selbst beobachten 
k8̈nnte. Er hat die Prinzessin schon zum Tode verurteilt, er sieht von seinen Augen ihre Todesagonie nach der Ver-giftung. Wieder spielt der Beichtvater Gott. Selne Erschllterung ist so gross, dass er sich gar nicht auf das Gespräch konzentrieren kann. Genau wie Tasso, leidet auch Martin an einer Ubermässigen Phantasie. Seine Phantasie sient das Leben in den dunkelsten Farben. Wo bleibt sein Glauben? Er ist ein Prister, aber er wilde gerne Gott sein. Nur wenn er "allgegenwärtig und unsichtbar" werden wirde, k8nnte or Elisabeth immer behllten und Immer an ihrer Seite sein. Martin verlangt von Gott mehr als einem Sterblichen gegeben ist, und das lat seine grösste Schwäche.

Auch macht er sich Vorwirfe, von jenem Beichtenden nicht die näheren Umstände des Mordplans "erforscht" zu haben. Aber lst eg tberhaupt mb̈glich, eine Beichte zu "erforschen"? Die Beichte soll eine freiwillige Verbindung zwischen Priester und Beichtkind sein. Und dann erinnert sich Martin plotzlich, dass or in selnem Schrecken das schuldbeladene Gewissen des Fremden vermachlässigt hat. Gerade um diese schuldbeladene Seele hat er sich wenig gektlmmert. Die Sicherheit der Prinzessin war und ist inm am wichtigsten.

Als Martin bemerkt, dass Elisabeth eine Katze und einen Kanarienvogel hat, fallt ihm plotelich ein, dass ein treuer Hund, der, kraftig und wachsam, seine Herrin immer begleite, Elisabeth elnigermassen beschiltzen könnte. Aber 
sein Vorschlag hat keinen Erfolg. Die Prinzessin kann leider Hundegeruch nicht leiden.

Die nächste Stufe in Nartins Strategie ist, sich so viel wie möglich in Elisabeths Nähe aufzuhalten. Er hat den Schildwachendienst für sie auf sich genommen. Sein grosstes Problem ist, dass er unbemerkt in inrer Năhe bleiben muss, Doch sein Amt kommt inm wieder zur Hilfe. Wenn die Prinzessin in inrem zimmer ist, wird er auf dem Korridor die vorgeschriebenen Brevierlesungen verrichten. Wenn Elisabeth Ball spielt oder im Garten sich aufhalt, wird er in inrer Năhe Brevier lesen. Diese Lesungen würden keinem auffallen. Aber wie kann er in Elisabeths Nathe sein, wenn die zur Jagd reitet? Er sieht vor seinen Augen nur die Bahre mit Elisabeths Leiche. Aber man soll nie fü einen Menschen, der noch lebt, schon das Grab grabenl Angst macht Martin blind gegen die Wirklichkeit. Er liest sein Brevier, aber seine Gedanken sind bel Elisabeth. Und zwei Herren zu dienen ist sehr schwer. Er denkt nur an inren Tod. "Was fur ein Tod ist inr zugesonnen?" fragt er sich selbst, "eine Kugel, ein Dolchstoss oder Gift?" (Seite 34). In seinem Geist hat er sie schon begraben. Und damit begeht er eine schwere sünde.

Gott umfasst die ganze Welt. Er steht uber allem Guten und allem Bösen, da er Schöpfer des ganzen Universums ist. So liegt auch die Schliessung des Grabens zwischen Gott und dem Menschen in seiner Hand...21 
Martin wird Detektiv. Er muss herausfinden, wer von den Dienerm am Schloss mit den Nörderm zusammenarbeitet. In seinen Gedanken uberprift er jeden Diener, jede Hausdame und jeden Gast. Ebenso wie Tasso, vertraut Martin keinem Menschen mehr. Alfons klagt uber Tasso, "...gegen viele hegt or ein Misatrauen, die, ich weiss es sicher, nicht seine Feinde sind". (Torquato Tasso. I. Aufzug, 2. Auftritt). Aber wenn dem Priester die Welt plotzlich "unwegsam und dunkel" scheint, erinnert er sich an Gott.. Er bittet Gott um Schutz filr die Prinzessin und um Beistand fur sich selbst. Er empfiehlt die Prinzessin inrer Schutzhelligen Elisabeth $(207-231 \mathrm{n}$. Chr.). Wie Tasso, findet Martin nur im Stillen und in der Einsamkeit Gott und Ruhe. Hat Martin endich die richtige Antwort auf sein Problem gefunden? "Die tiefgte Beugung des Menschen ist zugleich selne hochste Erhebung."22

Jeden Morgen liest Martin in der Schlosskapelle die Messe. Diese tägliche Predigt sollte eine"Beugung vor Gott" sein, aber fur Martin ist sie nur eine Gelegenheit, die Aufmerksamkeit der markgraflichen Familie zu fesseln. Er kann sich auf die Predigt gar nicht konzentrieren, da seine Gedanken nur um Elisabeth kreisen. Das Motto dieser Erzăhlung kơnnte deshalb sein. "Elisabeth vor Gott" das Motto Tassos;"der Diohter am Hofe von Ferrara". Martin glaubt der Erwânlte Gottes zu sein, um Elisabeths Rettung wenigstens zu versuchen. Er weiss. dass El1sabeths Lebensaussichten sich bessern wirden, 
wenn sie sich nicht im Schloss befande. Sie konnte zum Beispiel religibse "Ubungen" in einem Kloster untermehmen. Dann konnte sie Gott dienen und zu derselben zeit Martins Herz erleichtern, denn da wirde sie in sicherheit sein. Allein auf Gottes Hilfe kann Martin sich nicht verlassen, und er selbst kann Elisabeth nicht jede Sekunde beschlltzen. Doch inre Eltern wollen die Zeit bis zur inrer Hochzeit mit Elisabeth zusammen verbringen. Nach diesem Misserfolg finlt sich Martin nur noch ein wächter, der seinen Dienst nie vernachlässigen darf.

Durch Martin zeigt uns Bergengruen, ob und wann ein Mensch das Recht hat, den Mut zu verlieren. Alles erscheint dem Beichtvater hoffnungslos. Er wird von Schwermut ergriffen, und das Schicksal wird mit jeder Stunde grausamer. Warum muss Martin so viel leiden?

Er/Bergengruen/geht mit psychologischem Scharfsinn an seine Gestalten heran: er entwickelt nicht aus derl Charakteren die Handlung, sondern schliesst umgekehrt aus den Handiungen auf die Charaktere und fugt dann, sich auf die Logik des Charakters stutzend, Handlung auf Handlung. 23

Aus Martins Ziegeln der Logik baut Bergengruen das Haus seiner Handlung, oder "das Haus des Schicksals". Aus Martins Leben hat der fremde Beichtende Irmis gemacht, doch gerade in der Begegnung mit seinem Schicksal findet sich der Priester wieder zu sich selbst. 9 Martin kann sich nicht verzeihen, dass er beinahe 
nichts uber den Beichtenden weiss. Er weiss nicht, ob dieser sich schon für den Mord vorbereitet hat. Wahrscheinlich beobachtet er Elisabeth jede Minute. Bisher ist nichts passiert. Konnte die Beichte nur ein boser Scherz gewesen sein? Ein :Vielleicht" folgt dem anderen. vielleicht hat der Fremde mit der Verschwornng und dem Mordversuch nichts zu tun. Vielleicht war der Fremde wahnsinnig? Fur eine kurze Minute kann Martin beinahe aufatmen. Aber nur filr eine Minute. Plotzlich flungt die Todesqual wieder an. Heute Morgen war doch Elisabeth nicht in der Kapelle... vielleicht liegt sle schon in Sterben? In diesem Moment kracht in Schuss. Martin bekreuzigt sich und läuft in den Garten. Ein Gartenarbeiter berichtet, dass der Markgraf versucht habe, vom Fenster aus, einen Bussard zu schiessen. Bergengruen steigert die Spannung bis ins beinahe Unerträgliche. Und darauf folgt eine kurze aber völlige Entspannung. Die Menschenseele muss in dieser kurzen Pause wieder neue Kräfte fur den năchsten Schicksalsschlag sammeln. Martin denkt weiter. Er hat keine Zweifel, dass der Fremde seine Beichte vor einem anderen Priester wiederholt hat und dass inm die Lossprechung wieder verweigert wurde. Wer könnte dieser unbekannte Priester sein? Martin fthlt plotzlich in brennendes Verlangen, mit diesem Geistlichen zu reden. Was funlte dieser andere Wissende? Beide Männer wissen dasselbe Geheimnis und leiden viel- 
leicht zugleich. Beide könnten sich einander inre Seelen entlasten.

Die Prinzessin ist krank, und jeden Tag beim Tisch fragt Martin den Leibarzt, wie es Elisabeth gehe. Er braucht seine ganze Willenskraft,"um seine Stimme im Gleichmass zu halten". Eines Morgens macht der Leibarzt lächelnd die Bemerkung, "dass Schollihas sich in Ansehung der Prinzessin einer weitgehenden Besorglichkeit hinzugeben scheine". Martin erscheint es plotzlich, als wenn alle Umsitzenden uber inn lachten. Er fragt danach nicht mehr, denn er darf unter keinen Umständen auffallen. Im Geheimen wartet Martin auf die Rllckkehr seines Oheims. Auch diese letzte Hoffnung wird inm genommen. Sein Oheim wird einen verlängerten Urlaub nehmen milssen. Und Nartin muss mit seiner Seele allein weiterkämpfen. Als Priester darf er seiner Pflicht niont ausweichen. Er muss Elisabeth bis zu inrem Hochzeitstag beschitzen. Erst dann willde die Gefahr vorbei sein.

Als einige Tage später Elisabeth wieder die Messe besucht, füht sich Martin froh wie schon lange nicht meht. Und or wird sogar noch froher, als Elisabeth inm nach der Sonntagspredigt erklärt, dass sie sich in der Tat geelisch weiter auf inre zuklinftigen Aufgaben vorbereiten wolle. Sie hat leider keine zeit mehr, um Latein zu lemen, so dass sie selbst theologische Werke lesen könnte. Deshalb winsche sie eine gemeinsame, regelmässig 
wiederkehrende Lesung $z u$ bestimmten Stunden. Martin soll der Vorleser und Ausleger sein..

Wie kann sich die Stimmung eines Menschen plotzlich andernl Auf einmal fthlt sich Schollhaas von einer therquellenden Freude erfasst. Wo sind die Schmerzen und die Enttäuschungen geblieben? Martin macht sofort Vorschläge fur die Lesestunden. Sogar Elisabeth muss thber seinen Eifer lächeln. Sie versichert inm, inre Elterm wirden inn über alles Nothere informieren. Es flallt inm sehr schwer zu warten. Die Stunden werden plotzlich zu Tagen, und Martin wird unruhig und ungeduldig. Aber auch die 1ängste Nacht kommt zu einem Ende. Eines Tages beginnt die Niarkgräin von den Lesestunden zu sprechen, und die Lesungen beginnen. Bergengruen lässt Martin nie ohne irgendeine Hoffnung, die wie in Regenbogen erscheint und wieder verschwindet. 
DIE GOLDENEN STUNDEN DER FREUDE

Des Menschen Aktionen und Passionen, sein Wanderm und Irren, sein Streben und Versagen sind umgriffen und gehalten von zweifachem Wunder, sind umfangen und getragen von doppel=tem Geheimnis. Denn jedes Menschenlebens Weg funrt in eine grosse lilebe. 24

Wenn man alle Menschen fragen wirde, ob sie mehr Freude oder Leid in inrem Leben gehabt haben, wirden die meisten antworten, dass die Nacht länger als der Tag gewesen sei. Wer nie gelitten hat, ist kein Mensch. Aber wer nie Freude gefthlt und weltergegeben hat, ist auch kein Mensch. Wer Freude săt, erntet Frieden und Liebe. Und wer sein Herz dem anderen offnet, dem wird die ganze Welt vor die Füsse gelegt.

Die zwei thglichen Lesestunden sind fur Martin goldene Stunden der Freude. Er kann nicht nur mit Elisabeth zusammen sein und das Gelesene mit inr besprechen er kann sie auch in dieser zwei Stunden am besten beschïtzen. Der Priester selber hat wenige glilckliche Stunden in dem Schloss erlebt, und deshald erfullen inn diese theologischen Vorlesungen mit grosser Freude. Statt seiner Brevierlesungen in den dunklen Korridoren des Schlosses darf er nun zwei Stunden in elnem gringoldenen zimmer verbringen. Mit Tassos Worten könnte Martin der Prinzessin flir sein grosses Glilck danken:

Welch einen Himmel bffnet du vor mir, O Furstin! 
Macht mich dieser Glanz nicht blind. So sen' ich unverhofft in ewig Glück

Aus goldnen Strahlen herrlich niedersteigen.

(II. Aufzug, 2.Auftritt)

Am Anfang der Vorlesungen gibt es viele Teilnehmer: den Markgraten und die Markgrafin, den Leibarzt und Elisabeth mit inren Damen. Fur den kleinen und einsamen Hof bedeuten diese Stunden eine schone Abwechslung von dem grauen Alltag.

Bergengruen beschreibt haupsächlich Martins Geflhle wăhrend dieser zwei Stunden. An Stelle der Einsamkeit hat ex jetzt Gelegenheit, mit anderen Leuten zusammen zu sein, und ein junger Mensch wie er braucht Gegellschaft. Der Geistliche funlt "einen Aufschwung des Herzens, als vermbge sein Blick inn durch die Blumen. Frtichte und Genien der Decke hindurch zu einer strahlenden himmlischen Blăue emporzutragen". (Das Belchtsiegel, Seite 65). Martin fuhlt ein inm selbgt unverstindliches Gllick. Er scheint vom Leben wieder umgeben zu sein. Der Schriftsteller zeigt uns auch, dass der Priester in ausgezeichneter Redner ist. Man kann seiner stimme die Aufmerksamkeit nicht versagen. Wenn das Gelesene auch theologischer Natur 1st, so wird doch jedes neu aufgenommene Wort fur Martin und seine Zuhorer ein Vergntigen. Ein grosser Irrtum ist es, das Evangelium Christi immer nur mit frommelnder Trübseligkeit zu betrachten. Das Evangelium ist eine Lehre der Freude. Jesus Christus verwandelte Wasser in 
Wein, so dass man die Hochzeit in Kaanan länger felern könnte.

Martin freut sich besonders auf die Lesepausen, wenn das Gelesene besprochen wird. Die Prinzessin stellt die erste Frage, vielleicht etwas schllchtern, aber Martin merkt bald, dass sie geistige Schärfe und Klarheit besitzt. Welch Unterschied zwischen zwel Prinzessinnen: Tassos Leonore kann "dle alten Sprachen" i und ist "Schülerin des Plato", Elisabeths Ausbildung dagegen ist eine"ungeordnete" gewesen. Doch inre natirliche Intelligenz befiehlt inr, uber jede gelesene zeile nachzudenken. Nartin fthlt sich wie ein Lehrer, der plotzlich eine begabte Schillerin entdeckt hat. Diese Schillerin fragt, und or gerbt "In Eifer, ja in Feuer", um auf ihre Fragen zu antworten. Langsem geht dieser Eifer auch auf die anderen Zuhörer uber. Die Diskussionen gleichen einem spannenden Tennisspiel. Das Eis zwischen Martin und seinen Zuhbrërm ist gebrochen, und eine vollkommene geistige Verbindung besteht zwischen dem Redner und geiner Hörerschaft. Auch der Leibarzt nimmt hafufig an den Diskussionen teil, aber besonders lieb ist dem Priester die Anwesenheit der Markgräfin. Er hofft noch immer, diese Frau fur seine Absichten zu gewinnen. Noch eine Hoffnung besteht: vielleicht wird Elisabeth doch den Wunsch haben, sich fur eine Weile in ein Kloster zurickziehen. Er brauchte nur diesen Wunsch in inr zu "entwickeln". Dann konnte sie auch 
inre Eltern dazu utberreden. Man sagt, dass Freude einen edlen Menschen adelt. Fur Martin leuchtet die Freude wie ein Stern, wenn die Nacht ringsum noch so trib ist. Er kann sich selbst nlcht verstehen. Der Tod kriecht schleichend herum und kann jede Minute ein junges Leben ausloschen, aber Martin spinnt verwickelte Pläne, die vielleicht gar nicht $z u$ verwirklichen sind.

Und dann plotzlich kommt der nächste Schicksalsschlag in der Gestalt eines fremden und zerlumpten Mannes, der eines Tages plotzlich an einer Korridorecke erscheint. Der Fremde spricht schlechtes Deutsch und kann Martins Fragen nicht beantworten. Später hort man, dass der Mann ein itelienischer "Tabulettkrumer" gewesen sei, nicht etwa in bezahlter Mörder. Marting Aufregung ist nicht umsonst gewesen, denn die Schlosswache wird nach diesem $\mathrm{Zwischenfall} \mathrm{verstärkt.} \mathrm{Der} \mathrm{Priester} \mathrm{fühlt,}$ dass er wenigstens etwas zum Schutz erreicht hat. Noch ein Erfolg für inn: filr seine gute Predigt zum Jahrestag einer Schlacht wird er von der Markgräfin beschenkt. Sie schenkt inm eine kostbare Ausgabe des lateinischen Buches De civitate Dei. Mit 22 Bilchern ist Der Gottesgtaat "die letzte grosse Apologie des Christentums gegen die Heiden, in der Augustinus (354--430 n. Chr.) den Kampr der Gottesblirger in der Kirche gegen die Erdenblirger, besonders im heidnischen Romerstat durch die Geschichte verfolgte." (Der grosse Brockhaus, Band I, Seiten 508-9). 
Aber weder das Lob noch das Geschenk können den Beichtvater von grauenerregenden Gedanken befreien. Er wird alles tun, um das Leben der Prinzessin zu retten. Aber wenn Gott es anders bestimmt hat? Vielleicht soll sie doch sterben? Darum muss Martin seinen zweiten Auftrag erfullen, er muss Elisabeth, ohne inr Wissen, auf den Tod vorbereiten. Inre Seele muss or "in einem Zustand bringen, im welchem sie jede zeit vor Gott treten k8̈nnte". Vielleicht könnte er Elisabeth mit den Worten aus De civitate Dei. Kapitel XI, trösten. Da behauptet Augustinus, dass der Tod nach einem vollwertigen Leben kein tbel ist... Wichtig ist nur da Leben im Jenseits. Deshalb soll der Sterbende sich nicht dartber sorgen, wie er stirbt, sondem, wohin er kommt, nachdem er gestorben ist.

In den Lesungen spricht Martin jetzt immer uber plotzlichen Tod und die Vorbereitung darauf. Unbemerkt wird Elisabeth das wichtigste Wesen in seinem Leben. Die Frage ist: wie sehr liebt Martin die Prinzessin?

Er /Bergengruen/ IHsst seinen Menschen einen Winkel in welchem sie vor unserer Neugier geborgen sind. Sie dirfen dort mit inrem Geheimsten allein sein, und es bleibt dem Anstand unserer Seele uberlassen, den Inhalt der nobel bewahrten Geheimnisse schweigend auszufuhren. 25

Dieser Winkel ist Martins Herz. Der Schriftsteller erklärt uns nichts, wir sollen unsere eigenen Schlüsse 
ziehen. Doch sogar in diegem Winkel wird Bergengruens Mensch "vor unserer Neugier" nicht bewahrt. Denn Neugier ist menschlich. Der Miensch stellt immer Fragen. Was sagt Bergengruen selbst dariber? "Wir /Dichter/ beantworten Fragen ja nicht mit der Erklärung, sondern mit der Gestalt, zum mindesten versuchen wir das."26 Der Dichter 14sst uns allein mit unseren Gedanken und unserer Kritik.

Martin beginnt an seinen Beziehungen zu Elisabeth selbst zu zweifeln. Seine Besorgnis um sieglaubt er seinem Amt als Priester schuldig zu sein. Gleichzeitig jedoch verbietet inm dieses Amt, das Beichtsiegel zu brechen. Sonst könnte er schon längst dem Markgrafen auf irgendwelche Weise berichten, dass Elisabeths Leben bedroht sei, und dann wirden sie und er selbst gut behutet sein.

Es geht so weit, dass Martin sogar das Schlosss nicht zu verlassen wagt. ,Gewisse Personen soll er besuchen, aber diese Menschen mit belasteten Seelen müssen vergebens auf inn warten. Seine blsherige Wohnung in He111g-Lelchnam wagt er nur dann aufzusuchen, wenn die Prinzessin eine Ausfahrt untermimmt. Und dann macht er diese Gänge mit Hast. Von seinem fritheren Ieben fithlt er sich schon geschieden. Es liegt in tiefer Abgrund zwischen dem Leben und inm, und dieser Abgrund ist das furchtbare Geheimnis, das er allein tragen muss. Nur die 
Lesungen verbinden ihn noch mit dem wirklichen Leben, und es ist inm ein wenig leichter, denn bisher ist nichts geschehen, und fur diesen unsichtbaren Schutz kann er Gott danken. Er darf auch annehmen, dass seine Wachsamkeit Elisabeth beschlitzt hat. Ausserdem lobt die Prinzessin jetzt zurilckgezogener als sonst. Die Vorlesungen treten in den Vordergmund und die Jagd und die Spazierfahrten werden seltener, denn Elisabeth liest jetzt viele Bltcher, bel deren Wahl die dich von Martin beraten lässt. Mit der zeit entziehen sich viele zunzrer den Lesungen. Nur die Prinzessin, Inre Damen und der Leibarzt bleiben. Martin merkt es kaum, "so sehr war er von dem ausschliesslichen Gedanken an Elisabeth erfullt". (Seite 89). Wenn das Gelesene besprochen wird, dann hat Nartin das Gefuhl, er verständige sich mit Elisabeth "uber die K8pfe der anderen hinweg. Es war Ihm als verkehrten sie miteinander in elner sprache, welche die Ubrigen Anwesenden nicht beherrschten, als umschlosse sie beide bereits der Raum eines gemeinsamen Gehoimnisses". (Seite 89) Wir erinnern uns plotzlich an Tassos gluhende Worte:

Da dacht' ich manchmal an mich selbst und winschte, Dir etwas sein zu können. Wenig nur, Doch etwas, nicht mit Worten, mit der Tat wilnseht ich's zu sein, im Leben dir zu zeigen, Wie sich mein Herz im stilien dir geweint.

(II. Aufzug, 1. Auftritt)

Der Dichter darf sein Herz 8ffnen, aber der Priester muss 
schweigen.

Je mehr Martin die Prinzessin liebt, desto weniger zeichen braucht er, um sie zu verstehen:

Aus seinen / Martins/ Worten stromte eine Glut, eine heimliche Süssigkeit und Leidenschaft, die inn selbst fortrissen. Ein Widerschein, mehr noch: eine Erwiderung solcher Stromnisse $\mathrm{kam}$ inm aus Elisabeths Augen entgegen. Er fithlte inre Seele in seiner Hand. (Seite 90)

Bergengruen zeigt uns hier das Band der Liebe, welches zwei Menschen unsichtbar fllr andere Augen verbindet. Niartin hallt Elisabeths Seele "in seiner Hand" und lebt im ewigen Licht. Aber nach dem lichten Tag kommt immer die dunkle Nacht.

Eines Norgens fragt der Leibarzt Martin plötzlich, ob er bemerkt habe, dass die Markgräfin schon seit längerer zeit die Iesestunden nicht mehr besucht habe. Er erklärt, dass der Markgraf und die Markgrafin "nichts

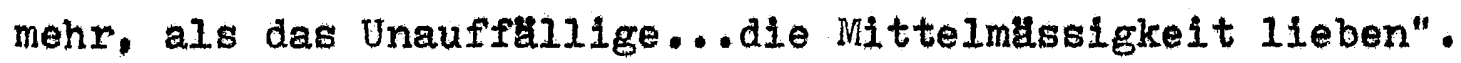
Gegen alles Ubertriebene haben sie eine Abneigung. Die Markgräfin liebe keine "Elnflüsse" und es wäre inr unerwïnscht, wenn die Prinzessin allzuweit "in einen Eifer der Frömmigkeit geriete". (Seite 93) Er selbst willde sich gar nicht wundern, wenn die Markgrafin die Lesestunden eines Tages abbrechen liesse. Am Ende des Gespräches gibt der Leibarzt Martin einen Rat, "So anziehend die Prinzessin ist--Sie müssen sich klar sein, dass keine 
Anntherung an sie unbemerkt bleibt. Halten sle sich zurick, streben sie nicht nach Neuerungen. Sie liefen Gefahr, eine Missstimmung zu erzeugen." (Seite 95)

Durch diese Worte wird der Uberempfindliche Priester von der Hothe seines Gluckes in die Tlefe innerster Verzagtheit herabgestossen. Martin ist bestilrzt nach diesem Gespräch. Am melsten trifft inn des Leibarztes Hinweis auf ein mögliches Ende der Lesestunden. Er denkt ther das Gespräch "voll Unsicherheit und zwiespalt" nach. Der Leibarzt also hat eine Anntherung zwischen Elisabeth und inm bemerkt. Und die Anderen? Kurz nach diesem Gespritch lässt die Markgrafin Martin auf die Terasse bitten und erklărt inm, dass die Hofgesellschaft ihm für die Lese-stunden sehr verpflichtet sei, aber die Prinzessin sollte sich jetzt mehr im Freien aufhalten." Sie ist auf ihre Aufgaben vorbereitet und soll jetzt nach den winschen inres Brăutigams Musik, Kartenspiel und Italienisch lemen. Die Markgrafin dankt inm auch diesmal mit einem augustinischen Buch Die Bekenntnisse. Und dann wird er entlassen. Die Bekenntnisse des Augustinus sind unsterblich, da dies Buch das Werk seines Lebens ist. Augustinus blindigte sein Ubermässig leidenschaftliches Temperament und wurde ein christlicher Mensch. Mit selner Philosophie der Liebe bewegt er auch heute noch die menschliche Seele. Er betrachtet die Liebe als unverginglich, wie ein stern, der uber dem verganglichen Leben strahlt. Nur in der Liebe unterscheiden sich die Kinder Gottes von den Kindern des 
Bbsen. Flir Augustinus ist Liebe das Mass aller Dinge. Wer an der Liebe sulndigt, begeht eine Sunde an Gott... Der Mensch soll sein elgenes Wesen verneinen und ganz im anderen Menschen aufgehen--gerade wie Martin das getan hat. Doch Augustinus selber war kein Vorbild in der Liebe zum Nächsten--er verachtete Ketzer und kämpfte gegen die Pelegianer. Eg ist auch nicht moglich, alle Menachen gleichmässig zu lieben. Sogar Christus konnte es nicht, er liebte Johannes mehr als seine anderen Jünger.

Auf seinem zimmer hat der Priester einen Tränenausbruch. Er hat physische und psychische Schmerzen. Der Unterschied zwischen beiden ist, die ersten vergisst man mit der zeit, aber die letzteren werden immer grausamer und gefährlicher. Martin funlt, dass er von Feinden umgeben ist, die schon die ganze zeit hinter seinem Rllcken geredet haben. Er könnte mit Tassos Worten klagen:

Ich fthle mir das innerste Gebein

Zersehmettert, und ich leb', um es zu funlen

Verzweiflung fasst mit aller wut mich an... (v. Aufzug, 5.Auftritt)

Frther hat er die Markgrafin sehr gerne gehabt, aber jetzt erscheint sie inm als ine kalte und listige Frau, die das Leben ihrer Tochter aufs Spiel setzt. Martin macht sich bittere Vorwlirfe. Er hat sich, wenn auch nur in Gedanken, der Prinzessin enger verbunden gefunlt, als 
einem Priester erlaubt ist. Doch was fur einen Eindruck hat er dabei auf seine Umgebung gemacht? Trifft der Abbruch der Lesestunden wirklich nur den "Beschlltzer" in inm?

Wenn einem Menschen die letzte Hoffnung genommen wird, dann beginnt er, langsam zu sterben. Wer inm diese Hoffnung raubt, stosst inn in den Abgrund. Sogar Prometheus, ein Ubermensch, konnte seine unendlichen und unerträglichen Schmerzen nur deshalb ertragen und aushalten, weil or die Hoffnung hegte, elnes Tages befreit zu werden. Nartin sieht keine Hoffnung mehr. Die einzige Freude ist inm genommen. Der Vothang ist uber die goldenen Illusionen gefallen. 


\section{IN HÖCHSTER VERZWEIFLUNG}

Die Angst ist da, seit der Mensch aus dem Garten gestossen und auf das Feld gefunrt wrurde, das ex nun unter mathe bebauen soll. 27

Die höchste stufe des leidens ist die Verzwelflung. Damit muss die Menschenseele kämpfen. Die Verzweiflung kommt und geht wie in Gewitter, und danach wird die Seele noch schöner und mächtiger als vorher. Der Mensch ist gerettet, wenn er ein Fenster in seinem Gefängnis des Leidens offnen kann. Der Lebensinstinkt mobilisiert den Widerstand gegen die Verzwelflung, aber die Ungewissheit lähmt den Menschen, und er wird passiv und krank. Die Frage ist, warum gerade gute Mensehen am meisten leiden milssen. Warum scheint das Böse über das Gute zu siegen?

Mit dem Ende der Lesestunden scheint es Martin, dass "dem Verlauf des Tages das Gerippe genommen" ist. Was ist inm ubriggeblieben? Ausser der Angst nur noch Schwermut, Einsamkeit, Misstrauen und eine ganz unerträgliche Zukunft.

Wenn Bergengruen seine Gestalten den innen besonders zugeordneten Raum des Schicksals betreten 1:̈sst, fuhrt or sie in eine Situation, in der es kein Ausweichen gibt. Die Tur wird hinter ihnen zugeschlagen, gie sind eingeschlossen in diesem Raum...28

Die Tir hinter Martin ist zugeschlagen. Er funtt sich 
allein in seinem Geflangnis der Verzweiflung. Genau wie Tasso, leidet auch Martin an Verfolgungswahn. Er vermutet Feinde tberall. Was kann er therhaupt noch filr Elisabeth tun? Er kann nur die Brevierlesungen auf den Korridoren wieder aufnehmen, aber er muss jetzt ganz unauffulif und vorsichtig sein, denn jede Anntherung an die Prinzessin wird beobachtet. Er kann Gott sein Leben

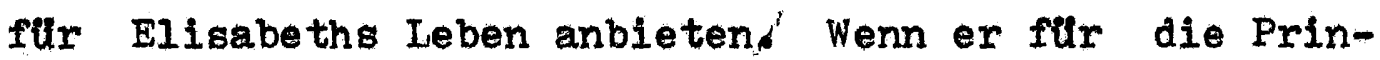
zessin nicht leben darf, dann will or fur sie sterben. Martin hat sogar die geheime Hoffnung, dass er ermordet werde. Aber willde sein Mord eine Losung des ganzen Problems bedeuten? Wer whirde dann Elisabeth beschultzen? Und dann erwägt Martin, dass er den Markgrafen um sofortige Enthebung von seinem Posten bitten k8nnte. Er könnte sogar weglaufen, aber wenn gerade danach die Untat geschähe? In seinen Gedanken sucht Martin einen Ausweg, aber alles ist umsonst. Er darf sogar den Bischof nicht besuchen, denn der Mord könnte ja zur gleichen zeit geschehen. Wie würde or dann mit seinem Gewissen weiterleben? Martin hat den Glauben verloren und "die Furcht ist allgegenwärtig und lauert ständig auf die Verfuhrung des Menschen und oft hat sie auch leichtes Spiel". 29 Wenn Martin nur ein wenig Gluck kutte, dann könnte er slch ruhig auf Gott verlassen, denn Er allein hält unsere Schicksale in Seiner Hand. Martin sollte darauf vertrauen, dass Sein Wille geschehe, aber die Angst ist mächtiger 
als der Glaube.

Obgleich in Christus die unerhörte Grösse der unfassbaren Gottesliebe dem Menschen sichtbar geworden ist, vermag er nlcht, dieser Verkilndigung zu trauen, sich inr einfach hinzugeben, sondern verharrt kleingläubig wieder in $Z$ weifel und Angst.

Aber die menschliche Natur ist kleinglaubig und misstrauisch. Gottesliebe scheint welt weg zu sein, und der Mensch wird von Angst uberwältigt. Die Welt scheint fur Nartin "eln Widersinn" zu sein, und doch macht er sich Vorwllefe, dass er seine Schutzpflichten vernachlässigt hat, um alle seine withe und alle seine Kraft den Lesestunden zu schenken. Man könnte sagen, dass Martin ein Pflichtmensch, aber kein Gottesmensch ist.

In dieser zeit seiner grössten Verzweiflung verl̆ndert sich der Priester nicht nur seeliseh, sondern auch äusserlich. Er sieht einem zeloten thnlich, mit seinen "fiebrisch glthenden" Augen und "vorgeschobenen Backenknochen". (Seite 113) Jede Freiheit des Gemllts ist verschwunden. Er funlt sich von allen beobachtet und verurteilt, obwohl er die Prinzessin nur selten sieht. Was denkt Elisabeth von ihm? Belde scheinen einander zu meiden. Martin hat Angst, Elisabeth zu treffen, denn er ist einem Nervenzusammenbruch nahe. Auch die Prinzessin hat sich verändert. Sie hat inre letzte kindliche spur verloren. Martin sieht, dass Elisabeth inm entwachsen ist. 
Inzwischen hat das Schicksal den năchsten Schlag fur Martin schon vorbereitet. Als er eines Tages mit Elisabeth und inrer Dame durch den Park geht, steht plbtzlich eine alte Bettlerin vor innen. Eine wargcheinliche Morderin? Die Frau bettelt um Geld, aber Martin fängt an, sie in der Gegenwart Elisabeths und Frăule in Beckums auszuschimpfen. Er verliert den Kopf, er denkt, dass er ganz allein ist. Angst hat inn tief erniedrigt. Ein Priester darf nie seine Geduld verlieren, denn Geduld ist die grösste Tugend eines Christen. Martin lässt die Frau gar nicht antworten, er droht nur mit Einsperren. Als die Bettlerin verschwunden ist, sieht Elisabeth den Priester befremdend an, und dann gibt sie inrer Dame ein Geldstlick, um der Bettlerin nachzueilen. Jetzt sind sie beide allein. Elisabeth sagt, dass sie sich vor Martin filrchte. Anschliessend fragt sie sorgenvoll, ob Martin Kummer habe, und sie fragt es so freundlich, dass es dem Priester sehr schwer fullt, sich zu beherrschen. Tiefe Bewegung therwaltigt inn fast. Aber dann kommt Frelulein Beckum zurlick. Der gefinrlichste Moment ist vorbei. Martin hat sich benommen, wie in Muttertler, dessen Junges von Jägern eigekreist ist.

Spltter findet er in seinen Gedanken doch Trost. Elisabeth hat Angst vor inm gehabt, trotzdem konmte sie gleich wieder freundlich und besorgt sein. Deshalb muss sle inn doch gern haben. Dieser Trost tut seinem zerwăhlten Herzen wohl. Zugleich aber scheint inm die Prinzessin 
"die Braut des Todes" zu sein, und seiner Meinung nack ist die Markgrlfil allein schuld daran, dass die Lesestunden abgebrochen wurden. Er fithlt es--gerade wie Tasso ist er ein Gefuhlsmensch. Es 18t menschlich, sich zu irren, denn gerade die Prinzessin hat den Abbruch der Vorlesungen gewilnscht. Warum? Martins Oheim, ihr Lehrer, hat die Welt fllr sie immer nur "weitergesteckt" und nicht "entgegengesetzt". wie Martin es getan hat. Und Elisabeth ist noch nicht weit genug von inrer Kindheit entfernt, um die Lehre des Oheims vergessen zu kb̈nnen. Die Lesestunden sind fur sie eine "entgegengesetzte Welt" gewesen, die sie langsam verwirrt hat. Martin selber scheint inr kein gewönnlicher Priester zu sein, sondern ein Mann "wie von den Farben der Legende gemalt". Dleser schöne Mann, der wie ein romischer Held aussieht, "riss den Vorhang plötzlich fur sie zu Seite" (Selte 128) Ein noues "seelisches Abenteuer" hat Martin in inr erweckt:

Er hatte ein Feuer entzindet, in dessen schreckhafter susse sie sich versengt funlte.

(Seite 128)

Elisabeth flhlt, dass sie einer Liebe nahe ist, und dieses neue Gefthl erweckt Angst in inr, denn Liebe und Angst gehen Hand in Hand. Sie ist inres Herzens nicht mehr sicher, und hat ein "Misstrauen gegentber dem Aussergewöhnlichen". Elisabeth merkt die Wandlungsfahigkeit in sich selbst. Sie vergleicht Martin sogar mit inrem 
Verlobten. Die Liebesflamme ist fur ihre zukunft gefährlich, und sie muss sie so schnell wie mbglich ausloschen. Das Leben ist fur Martin sinnlos geworden. Seine Hände sind gebunden und alle Wege verspert. Das Fenster in seinem Gefängnis des Leidens bleibt geschlossen. Er ist von Angst schon so vergiftet worden, dass er keine Rettung fur inn gibt. Die Krefte verlassen inn von Stunde zu Stunde. Martin wird apathisch. Sogar die Rluckkehr seines Oheims bereitet inm keine Freude mehr. Auch die Zeit hat keine Bedeutung mehr fur inn. Es sind ja nur Gottesstunden, die vergehen. Das Sprichwort sagt, man solle seine zeit wahmehmen! Martin hat Elisabeth auf inren Tod vorbereitet. Vielleicht sollte er jede Minute ausnutzen und sich selbst auf "seinen eigenen Tod vorbereiten". (R11ke) 
DER BESUCH DES FRENDEN GASTES

\begin{abstract}
"Der Gast", so nennt Bergengruen den Tod einmal. Dadurch ist dem Tode sein Stachel schon genommen. 31
\end{abstract}

Frthe Christen haben Schmerzen verherrlicht. Ieiden natherte sie dem Tode und damit Gott. Das irdische Leben war fltr sie unwichtig, das einzig wahre Leben bestand im Gottesreith. Da das jenseitige Leben nur durch den Tod erreicht werden konnte, sehnten sie sich ihr ganzes Leben lang nach dem Tode...

Mit jeder Minute und jedem Herzschlag kommen wir dem Tode nather. Wir konnen an Gott, Unsterblichkeit und Leben zwelfeln, aber den Tod kann keiner verneinen. Und doch lebt der Mensch, als ob es keinen Tod gelbe. Er lacht und weint und versucht sein ganzes Leben lang, die Todesangst zu Uberwinden. Nicht die Angst vor dem Tode selbst, sondern die Angst vor dem Sterben plagt uns.

Ist der Tod schrecklich oder gut? Bergengruen kennt kein verkrampftes Jenseitsgefuh1... Bel inm ist nicht Sterbenkönnen die grösste Kunst, der Tod ist nur ein Teil. Das Leben ist Bergengruen ebenso wichtig. Die Harmonie aus diesen Gegensatzen ist $\mathrm{es}$, was or anstrebt. 32

Wenn ein Mensch vor Angst nicht mehr schlasen kann, ist sein Leben gefahrdet. Martins Nächte sind unerträglich geworden, und er weiss nicht mehr, wo die Alptrkume enden und wo die Wirklichkeit beginnt. Eines 
hachts weckt inn ein Schuss. Doch ist es kein Schuss, sondem nur ein Klopfen an der Tü. Ein Junge von dem Gasthaus "Roter ochs" holt Hochwiliden, da einer der Gabte im Sterben liege. Es ist zwei Unr nachts. Der Vierzehrfathrige erklkirt, dass er den Namen des kranken Handelsmannes nicht wisse. Dieser soll plotzlich erkrankt sein und habe dringend gebeten, zum Priester Scholihas aus Schloss zu schicken.

Nachdem Martin sich in der Sakristei mit den fur die Sakramente Erforderlichen versehen hat, geht or mit dem Jungen zum Gasthaus. Er muss tiber Leben und Tod nachdenken. Er fthlt "dass zwischen dem Himmel und der Erde die Nathe und Entfernung nicht in den Massen der Menschen zu messen wăren". Gerade wie zwischen Leben und Tod. Diese zwei gehen Hand in Hand, und ohne das Elne wille auch das Andere unmbglich sein. Das Leben ist eine Vorbereitung auf den Tod. Der Tod vergisst uns nie, doch ein schneller und schmerzloser Tod ist Gottes h8chste Gnade auf Erden.

Die Nacht ist feucht und trtb, aber Nartins Herz ist froh. Ihm ist etwas von der alten "Eindeutigkeit seines Amtes"zurilckgegeben. Er ejlt einen fremden sterbenden trobsten. Gleich in dem ersten Augenblick hat Martin in dem Sterbenden jenen Beichtenden erkannt. Die alte Erregung steigt dem Priester wieder in die Kehle. Seit Wochen hat inn dieser Mann in seinen Gedanken gequalt. Der Kranke erklibt, er habe Gift genommen. Er mbohte beichten, 
denn sein Ende sei nahe. Bei dem Licht einer Kerze bereitet sich Martin fir die Beichte vor. Aber alles, was der Mann sagen kann, ist:"Ich armer, stindiger Mensch bekenne..." In diesem Augenblick fallt ein Schuss, und die Beichte bleibt unausgesprochen. Der Fremde stirbt vor Martins Augen. Der Tod hat einen Menschen ausgewathlt. Und wen der Tod einmal auswathlt, von dem lasst er nlcht mehr ab. Martin wird von Furcht uberkommen. Wir können unser Leben für andere Mitmenschen opferm, aber an inrer Stelle sterben, können wi nicht und das ist das shrecklichste. Doch

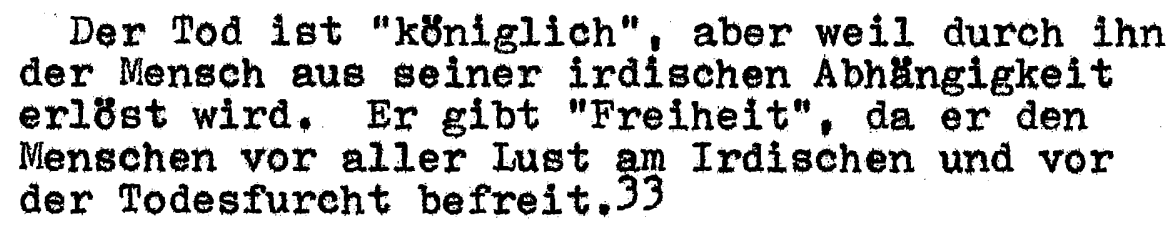

Wir wissen nicht, wieviel der Fremde gelitten hat, aber jetzt lst er frei von allem Leiden und der ewigen Angst. Er braucht sogar nicht mehr beichten.

Als Martin sich tiber den Getroffenen beugt, kracht es nochmals, und der Priester fällt seitwäts Uber das Bett. Dreimal offnet Martin die Augen. Das erste Mal sieht er Băume, Hăuser und spllrt die Fruhsonnenstrahlen auf seinem Gesicht. Das zweite Mal erfährt er, dass er auf einer Bahre getragen wird. Das dritte Mal sieht er das Schloss mit dem Schlossturm. Von seinem Dache weht die Fahne, die auf Halbmast hängt und schwarz umflort ist. 
Martin schreit auf. Inm wird erklürt, dass Elisabeths Verlobter, der Erbprinz Georg Phillip, gestern auf der Jagd durch ein Sturz vom Pferd zu Tode verunglückt sei. Diesen Morgen habe ein Kurler die Nachricht gebracht.

Martin versteht, dass die Gefahr filr Elisabeth vorbei ist. Alle Zweifel sind nichtig. Er llachelt gllicklich-vielleicht zum ersten Nal selt langer zeit. Er hat die Angst therwunden. Wïrde Martin sterben, so willde seine Seele doch weiterleben, gerade wie das Glas in Bergengruens Gedicht "Bestimmung" :

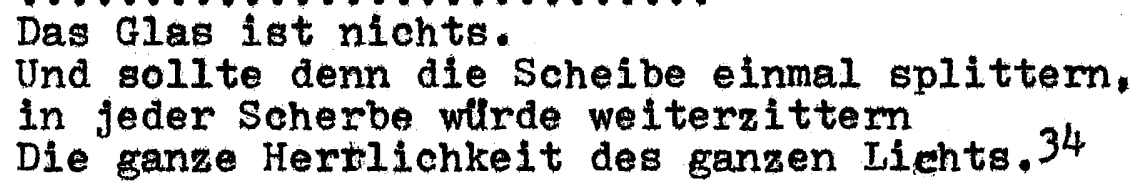


DIE SEELENPROBLEME IM SPIEGEL DES SCHRIFTSTELLERS

Manche Schriftsteller lieben es, das Thema des Seelenkonflikts zu behandeln, manchmal sogar in mehreren inrer Werke. Schon in seinem ersten Roman Das Gesetz des Atumg (1923) befasst sich Werner Bergengruen mit der Schuld und dem schliesslichen Untergang eines jungen Studenten. In dem Roman Der Grosstyrann und das Gericht (1935) regiert ewige Angst. Durch eine geheimnisvolle, Mordtat stïrzt der Grosstyrann seine Untertanen in Schuld, Angst und Irrnis. In dem Roman Am Himmel wie auf Erden (1940) werden der Kurfurst von Brandenburg und seine Untertanen von Todesangst uberwaltigt. Eine Flut wird prophezeit und der Weltuntergang scheint nahe. Bergengruen betont, dass kein Mensch von Todesangst und Gefahr verschont wird. Doch alle Schrecken sind zu uberwinden. Angst geh8rt auch zu der ewigen Ordnung Gottes und nur Er kann eine Menschenseele davon befreien.

Das streben der Menschheit hat langsam die verschiedene Türen der unbekannten Wissenschaften geoffnet. Der Mensch spiegelt sich in seinem Erfolg oder seine Kultur; doch seine seelichen Probleme kann or noch immer nicht lösen. In Bergengruens Werken sehen wir verschiedene seelische Probleme. Wie ein Kunstler malt or fur den Leser Menschenbllder und zeigt sie im richtigen Licht. Dann setzt er diese Bilder in alte, goldene Rahmen. 
Bergengruen schrieb Das Beichtsiegel 1946, als or in zürich wohnte. Die spannende Handlung in dieser Novelle spielt sich in einer Menschenseele ab. Der Ort der Handlung ist die Seele Martins, worllber Gott herrscht, aber wo Martin selber herrschen möchte. Doch kein Mensch kann uber seine Seele herrschen--ebenso wenig wie er ther seine Geburt und seinen Tod herrschen kann. Martin ist ein Mensch in Verwirsung. Einerselts will er abermenschliches leisten--Elisabeth vom Tode zu retten--andererseits aber klammert er sich an den Boden der Unwissenheit und Angst. In seinen Werken befasst sich Bergengruen mit Seelenkămpfen der Menschen. Neben dem Lebensinstinkt sind Neugier und Angst die mächtigsten Urgefuhle, denn der Mensch ist in neugieriges Wesen. Er fragt und zweifelt sein ganzes Leben lang. Auf jede Frage will er eine Antwort haben. Wenn er sie gefunden hat, wird er sie entweder annehmen oder ablehnen. Der Kreis dieses ewigen Strebens nach Wahrheit ist das Kennzeichen des Menschen. Bergengruen versucht uber den Kampf zwischen diesen arel Urgefthlen und der ewigen kosmichen Ordnung hinauszukommen. In dem Beichtsiegel betont Bergengruen den Kampf zwischen Miartins Glauben und seiner Angst. Er fuhrt den Leser bis an die fermsten Grenzen einer Menschenseele und lässt den Leser in den tiefsten Winkel dieser Seele hineinschauen.

Der Lebensbaum hat zwei Wurzeln! Schmerzen und Freude. 
Jeder Mensch wird durch Schmerzen geboren, und er muss sein ganzes Leben im Schmerzen verbringen. Durch Viartins Gestalt zeigt uns Bergengruen, dass es dem Menschen unmbiglich ist, tbermenschlich zu werden. Martin lebt in tiefster Verzweiflung. Er verguch vergebens, dem chaotischen Leben zu entfliehen. Die grosste Schwliche Martins ist, dass or im I'lefsten seines Herzens nicht auf Gott vertraut. Die Bibel lehrt, dass wir unersohltterliches Vertrauen in die Allmacht Gottes und seinen Ratschluss haben sollen. Dagegen verstösst der Priester, indem er sich von seinen Phantasien trelben lässt, die inm den Tod Elisabeths vorgaukeln. Martins Seelenruhe ist hin. Sein Zweifeln an Gott muss er mit Angst bezahlen. Endlich muss or doch zugeben, dass Elisabeth inr eigenes Schicksal annehmen, ertragen und erfullen muss, und dass er nicht inr Schicksal tragen kann. Denn Gott bestimmt das Schicksal jedes Menschen:

Ich bin filcht mein, du bist nicht dein. Keiner kann sein eigen sein. Ich bin nicht dein, du bist nicht mein. Keiner kann des andern sein. 35

Martin und Tasso können beide dem $Z$ wang der Seele nicht entweichen, genau wie "Die Zwiespäligen" Im Bergengruens Gedicht:

Wir sind gemacht, in Widerspruch zu schweben, zu fluten und saturnisch zu versteinen. Und eine Hand nur kann das Siegel heben. 36 
Das Verhalten jedes Menschen der Zwiespalt gegenllber ist anders, aber auch die jeweilige $\mathrm{zwiespalt}$ ist nicht die gleiche. Tasso schwankt zwischen der Persönlichkeit, die or ist, nämlich der weltfremde, unsichere Dichter, und der Persönllchkeit, die er sein möchte: der kinle, uberlegene Diplomat. Seine seele wird bald in die eine Richtung und bald in die andere Richtung gerissen. Martin steht auf der Grenze zwischen pflicht und Liebe, Von dieser unerträglichen Situation entwickelt sich das Seelendrama. Tasso und Martin sehnen sich instinktiv nach Schutz und Verständnis, aber anstatt Schutz finden sie Verzweiflung. und anstatt Verständnis Einsamkeit. Angst ist eine mächtige Waffe der Seele. Beide Manner sehnen sich nach dem Tode, aber dieser wird ihnen versagt. Das Schicksal ist nicht barmherzig', es belegt die Helden dieser Seelendramen mit der holchsten Strafe--dem Leben. 
1 Klemens Freiburg-Ruter, "Die geistige Welt der Lyrik Werner Bergengruens", Wirkendes Wort, 7. Jahrgang, $(1956 / 57), 1$. Heft, seite 17.

2 Werner Bergengruen, Privilegien des Dichters, zurich, (1957), Seite 71.

3 Gunther Klemm, "Wermer Bergengruen". Dichtung und Deutung, Heft 2, (1954), Seite 21 .

4 Klemm, seite 7.

$5 \quad$ Klemm, seite 2..

6

Klemm, Seite 9.

$7 \quad$ Privilegien des Dichters, Seite 85 .

8 Elisabeth Sobota, Das Menschenbild bel Bergengmen. Einfuhrung in das Werk des Dichters, Zlirich(1962), Seite 100.

9

Hans Bänziger, Werner Bergengruen: Weg und Werk,

Bern und Minchen, (1961), Seite 53.

10 Sobota, Selte 101.

11 Sobota, Seite 110.

12 Wilhelm Grenzmann, "Werner Bergengmuen (Offenbarmacher ewiger Ordnungen)" Dichtung und Glaube, 2. Auflage, (1952), Selte 219.

13 Freiburg-Rlter, Seite 17.

14 Gerhard Weiss, "Das Haus des Schicksals als Ausgangspunkt in der Prosawerken Werner Bergengruens". Monatghefte fur deutschen Unterricht. IIII, seite 291.

15 Weiss, Seite 292.

16 Grenzman, Seite 223. 
$17 \quad$ Klemm, Selte 45.

18 Klemm, Seite $76 .$.

19 Peter Baumann, Die Romane Werner Bergengruens, zurich (1968), Seite 58 .

20 Grenzmann, Seite 223.

21 Wolfgang Weber, Zur Lyrik Werner Bergengrueng, Wintenthur (1958), Seite 43-44.

22 Klemm, Seite 56.

23 Grenzmann, Seite 220-221.

24 Theoderich Kampmann, Die Welt Werner Bergengruens,

Warendorff in Westfalen (1952), Seite 58.

25 Peter Schifferl1 (Verfagser), Dank an Werner Bergengruen, zurich, (1962). Seite 168 .

26 Privilegien des Dichters, Seite 91.

27 Schifferli, seite 168-169.

28 Weiss, Seite 294.

29 Baumann, Seite 50.

30 Klemm, Seite 78.

31 Weber, Seite 28.

32 Weber, Seite 56.

33 Wober, seite 33.

34 Bergengruen, Werner, Die heile Welt, Verlag der Arche, zurich, (1962), Seite 219.

35 Die heile welt, Seite 165.

36 Die heile Welt, Seite 79. 
Blnziger. Hans. Werner Bergengruen: Weg und Werk, Berm München: Verlag Francke (1961)

Baumann, Peter. Die Romane Werner Bergengmens, Dissertation, zurich: Buchdruckerei Freidmter, (1954)

Bergengruen, Werner. Das Belchtsiegel, Zurich, Verlag von der Arche, (1968)

Bergengruen, Wemer. Die heile Welt, Ztirich, Verlag von der Arche. (1962)

Bergengruen, Werner, Privilegien des Dichters, Herausgegeben von Reinhold Schneider, Zurich: Verlag von der Arche. (1957)

Bergengruen, Wermer. Schreibtischerinnerungen. Minchen: Nymphenburger Verlag. (1961)

Freiburg-Ruter, Klemens. "Die geistige Welt der Iyrik Werner Bergengruens". Wirkendes Wort, 7. Jahrgang $(1956 \% 57), 1$. Heft, Selten 17--27.

Goethe, Johann Wolfgang. Torquato Tasso, Stuttgart. Philipp Reclam Jun., (1964)

Grenzmann, Wilhelm. "Werner Bergengruen (Offenbarmacher ewiger Ordnungen)". Dichtung und Glaube, 2.: Auflage (1952), Seiten $217-240$.

Kampmann, Theoderich. Die Welt Wemer Bergengruens, Warendorf in Westfalen: Verlag J. Schneliste Buchhandlung, (1952)

Klemm, Gunther. "Werner Bergengruen". Dlchtung und Deutung, herausgegeben von Helmut 0llesch. Heft 2 , (1954)

Schifferli, Peter (Verfasser). Dank an Werner Bergengruen. zurich: Verlag der Arche, (1962)

Sobota, Elisabeth. Das Menschenblid bel Bergengruen: Einfuhring in das Werk des Dichters. Zurich: Verlag der Arche, (1962)

Weber. Wolfgang. Zur Lyrik Wemer Bergengmens, Wintenthur: Verlag Keller, (1958)

Weies, Gerhard. "Das Haus des Schlcksals als Ausgangspunkt in der Prosawerken Werner Bergengruens". Monatshefte fur deutschen Unterricht, LIII, Seiten 291-297. 